\title{
Coleoptera genome and transcriptome sequences reveal numerous differences in neuropeptide signaling between species
}

\author{
Jan A Veenstra ${ }^{\text {Corresp. } 1}$ \\ 1 INCIA UMR 5287 CNRS, University of Bordeaux, Bordeaux, France \\ Corresponding Author: Jan A Veenstra \\ Email address: jan.veenstra@u-bordeaux.fr
}

Background. Insect neuropeptides are interesting for the potential their receptors hold as plausible targets for a novel generation of pesticides. Neuropeptide genes have been identified in a number of different species belonging to a variety of insects. Results suggest significant neuropeptide variation between different orders, but much less is known of neuropeptidome variability within an insect order. I therefore compared the neuropeptidomes of a number of Coleoptera. Methodology. Publicly available genome sequences, transcriptomes and the original sequence data in the form of short sequence read archives (SRAs) were analyzed for the presence or absence of genes coding neuropeptides as well as some neuropeptide receptors in seventeen beetle species.

Results. Significant differences exist between the Coleoptera analyzed here, while many neuropeptides that were previously characterized from Tribolium castaneum appear very similar in all species, some are not and others are lacking in one or more species. On the other hand, leucokinin, which was presumed to be universally absent from Coleoptera, is still present in non-Polyphaga beetles. Conclusion. The variability in neuropeptidome composition between species from from the same insect order may be as large as the one that exists between species from different orders. 
4

5 Coleoptera genome and transcriptome sequences

6 reveal numerous differences in neuropeptide

7 signaling between species

8

9 Jan A. Veenstra ${ }^{1}$,

10

11

12

13

14

${ }^{1}$ INCIA UMR 5287 CNRS, University of Bordeaux, Pessac, France.

Corresponding Author:

Jan A. Veenstra ${ }^{1}$

INCIA UMR 5287 CNRS, Université de Bordeaux, allée Geoffroy St Hillaire, CS 50023, 33615

Pessac Cedex, France

17 Email address: jan-adrianus.veenstra@u-bordeaux.fr 


\section{Abstract}

20

21

22

23

24

25

26

27

28

29

30

31

32

33

34

35

36

37

38

39

40

41

42

43

44

45

46

47

48

49

50

51

52

53

54

55

56

57

58

59

Background. Insect neuropeptides are interesting for the potential their receptors hold as plausible targets for a novel generation of pesticides. Neuropeptide genes have been identified in a number of different species belonging to a variety of insects. Results suggest significant neuropeptide variation between different orders, but much less is known of neuropeptidome variability within an insect order. I therefore compared the neuropeptidomes of a number of Coleoptera.

Methodology. Publicly available genome sequences, transcriptomes and the original sequence data in the form of short sequence read archives (SRAs) were analyzed for the presence or absence of genes coding neuropeptides as well as some neuropeptide receptors in seventeen beetle species.

Results. Significant differences exist between the Coleoptera analyzed here, while many neuropeptides that were previously characterized from Tribolium castaneum appear very similar in all species, some are not and others are lacking in one or more species. On the other hand, leucokinin, which was presumed to be universally absent from Coleoptera, is still present in non-Polyphaga beetles.

Conclusion. The variability in neuropeptidome composition between species from from the same insect order may be as large as the one that exists between species from different orders.

\section{Introduction}

Many neuropeptide signaling systems are commonly found in both protostomian and deuterostomian species, showing that most neuropeptides originated very early (e.g. Elphick, Mirabeau \& Larhammar, 2018). Indeed it is well established that genes coding neuropeptides and their receptors are well conserved during evolution and this is not surprising as they are important regulators of a variety of physiological processes.

Neuropeptide evolution consists of differrent phenomena, on the one hand are gains of novel neuropeptides and losses of existing ones, on the other hand are structural changes of the neuropeptides themselves, which are usually minor, but sometimes significant. When one compares the neuropeptidomes of decapod crustaceans with those of insects, it becomes apparent that few new neuropeptides have evolved since the existence of their last common ancestor, but that in insects a relatively large number of neuropeptide genes has been lost (Veenstra, 2016a). It would be interesting to have a better understanding of neuropeptide loss in order to get a better perspective on how it is possible that very ancient and well conserved regulatory systems can be lost in some species but remain apparently essential for others.

Tribolium castaneum was one of the first beetle species for which a complete genome sequence was published (Richards et al., 2008). As the genes coding neuropeptides and their receptors were identified it became clear that at least three neuropeptide genes that seemed to be universally present in insects, i.e. those coding for corazonin, leucokinin and allatostatin A, were absent from this species (Li et al., 2008). An observation that was confirmed by the absence of 
60 genes coding for the receptors of these neuropeptides (Hauser et al., 2008). The genes for two 61 other well known insect neuropeptides, pigment dispersing factor (PDF) and neuropeptide F 62 (NPF) were neither found in this genome (Li et al., 2008), although receptors for such peptides were identified (Hauser et al., 2008). It thus appeared that the sequences of the latter two peptides might have evolved so much, that they can no longer be easily identified based on sequence homology using the BLAST program. This raises the question as to whether these peculiarities, i.e. the absence of three common insect neuropeptides and the apparent structural modification of two others, are characteristic of all Coleoptera and thus characteristic of this insect order, or whether they are more limited and specific for this particular species or family.

The public genome sequences for sixteen Coleoptera species (Richards et al., 2008;

Keeling et al., 2013; Cunningham et al., 2015; Vega et al., 2015; McKenna et al., 2016; Meyer et al., 2016; Tarver et al., 2016; Ando et al., 2018; Fallon et al., 2018; Gautier et al., 2018; Kraaijeveld et al., 2018; Schoville, 2018; van Belleghem et al., 2018a,b; Wu, Li \& Chen, 2018) should make it possible to identify their complete neuropeptidomes and answer this question. Given that Tenebrio molitor once was the most studied beetle, as still evidenced by the number of publications that can be retrieved for this species on PubMed, I have added it to the list, even though only transcriptome data are available for this species.

Neuropeptides act through receptors and these may also be lost or amplified. In Chelicerates several neuropeptide G-protein coupled receptors (GPCRs) are amplified multiple times (Veenstra, 2016c). Yet I have not systematically checked whether neuropeptide receptors might be duplicated or lost. In the absence of a neuropeptide gene duplication, receptor duplication is likely to fine-tune the effects of its ligand, but this is difficult to establish. The fruitfly is no doubt the best studied insect species and while it is known to have two different allatostatin $\mathrm{C}$ receptors, the physiological significance of having two instead of one, like most insect species, is unknown. Therefore, receptors were only studied when the ligand appeared to be absent and in those cases where a neuropeptide gene was duplicated.

\section{Materials \& Methods}

\section{Definition of neuropeptide}

The definition of neuropeptide is sometimes ambiguous as in principle any peptide from the nervous system could be called a neuropeptide. In this manuscript neuropeptide is defined as a peptide or protein that is either released into the the hemolymph, directly on a target tissue, or within the nervous system to regulate cellular activity by interaction with a specific cell surface receptor, usually a GPCR. A large number of such neuropeptides has been identified by biological activity on target tissues and/or by directly activating their receptors, while others been identified only by their homology to known neuropeptides. Some neuropeptides have been identified solely on the basis of being produced after proteolytic processing of proteins of unknown function or even only on the basis of the strong likelihood that their putative precursors could be processed by neuroendocrine convertases into neuropeptides. The latter are hypothetical 
99 neuropeptides only and are more properly called putative neuropeptides. Indeed, a recent

100 analysis of the precursor of the salivary gland salivation stimulating peptide from Locusta

101 migratoria suggests that it is not a neuropeptide after all (Veenstra, 2017). These putative

102 neuropeptide precursors have been included here, even though no physiological effects have

103 been described for these peptides and their receptors are unknown. On the other hand, I have not

104 included the putative antidiuretic peptide identified from Tenebrio (Eigenheer et al., 2002). The

105 definition given above does not exclude it from analysis, but it is almost certainly derived from a

106 cuticle protein (CAA03880). Although there is a one amino acid difference between the C-

107 terminus of the reported sequence of this cuticle protein (Mathelin et al., 1998) and the

108 antidiuretic peptide that was sequenced, when constructing a Tenebrio transcript with Trinity

109 using the various RNAseq SRAs from this species the C-terminus of this proteins was found to

110 be completely identical to the antidiuretic peptide. There are no structure activity data with

111 regard to its antidiuretic activity and and it is unclear which protease is responsible for cleaving it

112 from the rest of the protein. This makes it difficult if not impossible to reliably predict which

113 other proteins might be the precursors of similar antidiuretic peptides.

\section{Sequence data}

115 Genome assemblies were downloaded from NCBI (https:/www.ncbi.nlm.nih.gov/genome) using

116 the following direct links: https://www.ncbi.nlm.nih.gov/genome/?term=Tribolium;

117 https://www.ncbi.nlm.nih.gov/genome/?term=Pogonus;

118 https://www.ncbi.nlm.nih.gov/genome/?term=Nicrophorus;

119 https:/www.ncbi.nlm.nih.gov/genome/?term=Aleochara;

120 https://www.ncbi.nlm.nih.gov/genome/?term=Oryctes;

121 https://www.ncbi.nlm.nih.gov/genome/?term=Coccinella;

122 https:/www.ncbi.nlm.nih.gov/genome/?term=Harmonia;

123 https://www.ncbi.nlm.nih.gov/genome/?term=Dendroctonus;

124 https://www.ncbi.nlm.nih.gov/genome/?term=Hypothenemus;

125 https://www.ncbi.nlm.nih.gov/genome/?term=Anoplophora;

126 https:/www.ncbi.nlm.nih.gov/genome/?term=Leptinotarsa;

127 https:/www.ncbi.nlm.nih.gov/genome/?term=Aethina), with the exception of the genomes of

128 Hycleus cichorii and H. phaleratus, which were obtained from the GigaScience repository

129 (http://gigadb.org/dataset/100405) and those of Photinus pyralis, Aquatica lateralis and Ignelater

130 luminosus, which were downloaded from http://fireflybase.org/firefly data.html. When

131 available, protein sequences predicted from the various genomes were also downloaded from

132 NCBI or the two websites mentioned using the same direct links indicated above. Predicted

133 proteins for Hypothenemus hampei were obtained from https://genome.med.nyu.edu/coffee-

134 beetle/cbb.html, and those for Aleochara the Animal Ecology department of the Free University

135 of Amsterdam (http://parasitoids.labs.vu.nl/parasitoids/aleochara/data.php). For Pogonus

136 chalceus the published transcriptome was useful (van Belleghem et al., 2012). To facilitate

137 reading, species will be identified by their genus name throughout this paper. In the case of the 
138 Hycleus species, this will refer to H. phaleratus. There are also two Harmonia genomes, but

139 these are from the same species and they showed no differences in the genes coding

140 neuropeptides. Four other Coleopteran genomes are publicly available, however they are not yet

141 officially published and for this reason were not fully analyzed here. Those are Sitophilus oryzae,

142 Diabrotica viriginfera, Onthophagus taurus and Agrilus planipennis.

143 Pogononus belongs to the Adephaga, all the other species to the Polyphaga suborder. The

144 genera Coccinella, Harmonia, Hypothenemus, Dendroctonus, Anoplophora, Leptinotarsa,

145 Aethina, Hycleus, Tenebrio and Tribolium all belong to the infraorder Cucujiformia. As will be

146 seen this group shares certain neuropeptidome characterics that are absent from the other

147 Polyphaga as well as Pogonus.

148 The quality of these genomes is quite variable. Some have excellent assemblies and in

149 addition numerous RNAseq SRAs making it possible to have high quality assemblies, others are

150 much more limited. For example, the Aleochara assembly has no RNAseq data and only a

151 limited amount of genomic sequences. In the case of Aleochara there is RNAseq data from a

152 different species, $A$. curtula (SRR921563, from the 1KITE project, Misof et al., 2014), which

153 was helpful and it allowed in some case to reconstruct exons missing from the assembly using a

154 combination of raw genome sequences and trinity. Nevertheless, it is still possible to ascertain

155 the presence or absence of neuropeptide genes from this assembly.

156 In several instances the predicted complete coding sequences of some neuropeptides are

157 incomplete. When there is little RNAseq data to deduce precursor sequences and a draft genome

158 contains large and small gaps in the assembly such sequences are often incomplete and may well

159 be incorrect in the parts that have been deduced. The Oryctes and Aleochara draft genomes

160 suffer the most from these problems.

161 A complete list of all SRAs used is available as supplementary data (Table S1).

\section{Presence of neuropeptide and receptor genes}

163 Predicted neuropeptide precursors were preferentially obtained from the annotated

164 genomes, but this was not always possible. On the one hand, small neuropeptide genes are often overlooked by automated annotation programs, even though progress has been quite impressive in that respect, on the other hand there are quite a few transcripts that are probably wrong. Thus many neuropeptide precursors were corrected or predicted de novo from RNAseq data by using the tblastn_vdb command from the SRA Toolkit

169 (https://www.ncbi.nlm.nih.gov/sra/docs/toolkitsoft/) on one or more SRAs using the Tribolium neuropeptide precursors as query to extract reads that could potentially encode a homologous protein. Those reads were then assembled using Trinity (Grabherr et al., 2011) and transcripts that might encode neuropeptides or other proteins of interest were then identified using BLAST + (ftp://ftp.ncbi.nlm.nih.gov/blast/executables/blast + ). Trinity produced transcripts were judged complete when the N-terminal of the predicted neuropeptide precursors had a signal peptide that could be identified as such by SignalP (Petersen et al. 2011) as implemented on the web (http://www.cbs.dtu.dk/services/SignalP/) and had an inframe stop codon at the C-terminus. For 
177 G-protein coupled receptors (GPCRs) the identification of the N-terminus is often more

178 ambiguous as some sequences did not have an in-frame stop codon upstream from the putative

179 ATG start codon. In those cases perceived similarities with homologous GPCRs were used as

180 criterium for completeness. However, for the GPCRs analyzed here the aim was not to obtain

181 absolutely perfect sequences for each receptor, but rather to show whether or not it is present in a

182 particular species.

183 When in a first round of analysis with the tblastn_vdb command incomplete sequences

184 were obtained, partial transcripts were then used as query for the blastn_vdb command to obtain,

185 where possible, the remainder of the putative transcripts. This process sometimes needed to be

186 repeated multiple times. Transcripts could also be completed by using the assembled genomes,

187 and in several instances no transcripts were obtained at all and only the genome was available.

188 Although many genes were located on single genomic contigs, this was not always the case. In

189 those cases either Trinity produced transcripts and/or individual RNAseq reads, or homology

190 with other precursors from other species were used to confirm the continuity of these transcripts.

191 It may be noted here that not all trinity produced transcripts are copies of mRNA species

192 of the genes their sequences seem to indicate. In a previous paper on the RYamide gene in

193 Drosophila melanogaster we showed that the very large majority of RNAseq reads that

194 correspond to the coding sequence of this neuropeptide in the various SRAs are not due to the

195 transcription of the RYamide gene, but rather parts of 3'-ends of mRNA produced from genes

196 located upstream (Veenstra and Khammassi, 2017). The RYamide gene is very little expressed

197 in D. melanogaster and mostly in only two neurons in the adult. This causes the RYamide

198 transcript to be so rare that virtually every RNAseq read that contains part of the coding

199 sequence of this gene is in fact an artifact and is not derived from an authentic RYamide mRNA.

200 It is likely that RNAseq reads from other genes that are neither extensively expressed, such as is

201 the case for many neuropeptide genes, may similarly be the product from a heavily expressed

202 upstream gene, rather than from the neuropeptide gene in question. This problem was $e . g$.

203 encountered with the PTTH gene from Hycleus and the Leptinotarsa periviscerokinin gene. Such

204 RNAseq reads attest to the existence of the neuropeptide gene in question, but have not

205 necessarily undergone the same splicing as the one that is imposed on the neuropeptide mRNA.

206 This phenomenon explains why certain Trinity produced transcripts predict mRNA sequences

207 that contain introns that have not been excised. Whereas in some cases such "false" transcripts

208 can be discarded easily due to the presence of an in-frame stop codon, in other instances such

209 stop codons are absent. Even though obviously such data reveal alternatively splicing, it is not at

210 all clear that this alternatively splicing actually occurs in mRNAs produced from the

211 neuropeptide gene. In other words, what at a first impression may look like very sloppy intron

212 processing, may in fact reflect sloppy stop codon processing in a gene upstream where such

213 sloppiness has no consequences. It is for this reason that I have made no effort to carefully

214 analyze all alternative splice forms for neuropeptide precursors and only recorded those that

215 seem authentic and physiologically relevant. 
216

217

218

219

220

221

222

223

224

225

226

227

228

229

230

231

232

233

234

235

236

237

238

239

240

241

242

243

244

245

246

247

248

249

250

251

252

253

254

The presence in RNAseq data of sequences that represent 3'-ends of primary mRNA sequences in which the polyadenylation signal has been ignored may lead to Trinity transcripts that are longer and extend into downstream genes. Thus many Trinity produced transcripts appear at first sight to lack a signal peptide, such transcripts were corrected by removing sequences judged to be extraneous based on sequence homology with other species and in the case of neuropeptide precursors on the presence of a credible signal peptide.

\section{Absence of neuropeptide and receptor genes}

The methodology described above allows one to demonstrate the presence of particular neuropeptide. However, when a particular gene is not identified in this way, it does not necessarily mean its absence from the species in question. When a gene is absent from the transcriptome, it may be simply because its expression levels are very low, as e.g. in the case of the previously mentioned RYamide gene from $D$. melanogaster. If the gene is also absent from the genome assembly, it is possible that it is located in a part of the genome that did not make it into the genome assembly.

Neuropeptides act via receptors, most of which are GPCRs. In many cases, but certainly not all, GPCRs are specific for a particular neuropeptide. So if a neuropeptide gene is genuinely missing from a species, one should expect its receptor to have lost its function and no longer be subject to positive selection. Hence, its receptor is expected to be lost as well. So, when both a neuropeptide and its unique receptor(s) are absent from a genome assembly, it is a good indication that the particular neuropeptide signaling system has been lost from the species in question.

For receptors that may be activated by neuropeptides derived from different genes, this argument can not be used. For example, a Bombyx myosuppressin receptor can be activated by both myosuppressin and FMRFamides (Yamanaka et al., 2005, 2006), hence if either the myosuppressin or FMRFamide were lost, this receptor could still be present. Similar situations likely exists for other neuropeptides, e.g. the CCHamides 1 and 2 (Hansen et al., 2011; Ida et al. 2012) or sNPF and NPF (e.g. Reale, Chatwin \& Evans, 2004). Thus missing neuropeptide receptors can only be used to validate the absence of a neuropeptide ligand, if these receptors are activated exclusively by that ligand.

The loss of a gene can in principle only be demonstrated by flawless genome assemblies (they don't exist), however there is an alternative, that is almost perfect. It exists in the analysis of the original genomic reads obtained for the assembly. When those reads are very numerous short reads, the chance that there is not a single read that covers the gene in question becomes extremely small and thus negligible. The only remaining problem than is the question, whether or not the gene in question can be reliably identified from a single short read. For the most GPCRs the answer to this question is yes, as the sequences of the seven transmembrane regions are strongly conserved and there are always a couple of them that one can unambiguously identify as being part of a particular receptor. Obviously, this might not work if all the individual transmembrane regions of a GPCR were coded by two exons interrupted by an intron. But this is 
255

256

257

258

259

260

261

262

263

264

265

266

267

268

269

270

271

272

273

274

275

276

277

278

279

280

281

282

283

284

285

286

287

288

289

290

291

292

not the case for the GPCRs analyzed here. An illustration of this method is provided as a supplementary figure (Fig. S1).

For the analysis of the absence of neuroendocrine convertase $\mathrm{PC} 1 / 3$ a similar procedure was applied. This was relatively easy, as this protein has a very well conserved primary sequence.

To demonstrate the absence of a particular neuropeptide gene in this fashion is much more difficult. First, many neuropeptide genes code for a single neuropeptide and the remainder of the precursor is often too poorly conserved to be recognized reliably in short genomic reads from species that are not closely related. Secondly, in some cases the sequence coding the peptide or its most conserved parts, may be interrupted by an intron. For example, the genomic sequences coding the neuropeptide $\mathrm{F}$ family all have a phase 2 intron in the triplet coding the Arg residue of the C-terminal Arg-Phe-amide, making identification of genomic sequences coding this peptide more difficult. A similar intron is present in the elevenin gene. Thirdly, some neuropeptides are not only small but are also made up of amino acids that have very degenerate codons, this is the case for short NPF (SNPF). Finally, sometimes conserved amino acids in a particular neuropeptide are no longer conserved, as is the case for allatotropin in honeybees and other Hymenoptera (Veenstra, Rodriguez \& Weaver, 2012). On the other hand, when dealing with a larger peptide that is structurally well conserved during evolution this would provide an additional argument for its absence.

\section{Sequence comparisons}

For comparing the sequences of various neuropeptides I have used Seaview (Gouy, Guindon \& Gascuel, 2010) and the figures it produces. The different colors that are used to identify amino acid residues with similar chemical characteristics (acidic, basic, aromatic, aliphatic etc) provide good visualization of conserved amino acid sequences when absolute conservation of residues is limited.

\section{Results}

\section{General comments}

Neuropeptides have previously been identified and sequenced for some of the species analyzed here. The sequences of the two sNPFs and the two AKHs that were identified from the potato beetle (Gäde \& Kellner 1989; Spittaels et al., 1996a) are exactly the same as those predicted from the genome. On the other hand there is no Leptinotarsa gene coding an allatotropin with the same structure as the allatotropin ortholog from Locusta migratoria, in spite of suggestions otherwise (Spittaels et al., 1996b) and this species has a proctolin gene that predicts a classical proctolin and not the previously reported [Ala ${ }^{1}$-proctolin (Spittaels et al., 1995a). Two other putative neuropeptides that were reportedly isolated from this species could neither be identified in any of the genomic or transcriptomic sequences analyzed here (Spittaels et al., 1991; 1995a). 
293

294

295

296

297

298

299

300

301

302

303

304

305

306

\section{7}

The sequences of Tenebrio AKH, myosuppressin, three pyrokinins, DH37 and DH47 as predicted here from the transcriptome are identical to those reported previously, the only difference being that the transcriptome suggests a C-terminal amide for DH47 instead of the reported C-terminal acid (Gäde \& Rosiński, 1990; Furuya et al., 1995, 1998; Weaver \& Audsley, 2008; Marciniak et al., 2013). The AKH sequences from Coccinella, Harmonia and Nicrophorus (Neupert, 2007; Gäde, Šimek \& Marco, 2015) are also identical to those deduced from the genome sequences.

The majority of the neuropeptide precursors seem quite similar in structure between the different species. Those will not be commented upon, but their sequences can be found in the supplementary data (Table S2; Supplementary Figures). To facilitate interpretation of the data several figures include a simplified phylogenetic tree of the species analyzed. This tree is based on the extensive phylogenetic tree recently published for Coleoptera (Zhang et al., 2018). When I use the term closely related species in the text, this is short hand for species that are neighbors on the simplified phylogenetic trees.

\section{Significant changes in peptide sequences}

\section{PDF, pigment dispersing factor}

The PDF present in Tribolium and other Cucujiformia has two more amino acid residues than the Drosophila peptide and differs from it especially in its C-terminal half (Fig. 1). This explains why it wasn't identified in a previous study (Li et al., 2008). In the other Polyphaga it is more similar to the Drosophila peptide, but in Polygonus it is two amino acids shorter than in Drosophila.

\section{NPF, neuropeptide F}

The structure of NPF has changed even more than that of PDF. It is relatively common for a Phe to resiude change into a Tyr and vice versa and so the mutation of the C-terminal ArgPhe-amide into Arg-Tyr-amide in most species studied here, is not unusual. More drastic is the presence of disulfide bridge in the N-terminal of NPF in the Cucujiformia and the mutation of the C-terminal Arg-Tyr-amide into a Pro-Tyr-amide in the two Curcuclionids. The primary sequence similarity of the predicted peptides to each other and other insect NPFs, as well as the characteristic phase 2 intron in the Arg residue (Pro in the Curcuclionids) of the C-terminal of these peptides confirm that these are true NPF orthologs (Fig. 2). I was unable to find an Oryctes NPF gene, although an NPF receptor seems to be still present in this species. Given the enormous structural variability of this peptide in Coleoptera it is not clear whether this is because the NPF gene was lost, or whether in this species the peptide has undergone even larger sequence changes. 
327 ACP

328 ACP is a peptide that has been lost independently at least three times and in those species

329 where the gene is still present the predicted peptide sequences are quite variable (Fig. 3).

330

331

332

333

334

335

336

337

338

339

340

341

342

343

344

345

346

347

348

349

350

351

352

353

354

355

356

357

358

359

360

361

\section{Baratin or NVP-like precursor}

Baratin is a small neuropeptide initially isolated from the cockroach Leucophaea maderae (Nässel, Persson \& Muren, 2000) that has been shown to be produced from a large neuropeptide precursor that has been called NVP-like in Tribolium (Li et al., 2008). This neuropeptide precursor is well conserved in Coleoptera (Fig. S2), except that in Dendroctonus it is lacking the last part as deduced from both in the genome and transcriptome sequences [note there is another baratin precursor at NCBI that is supposedly also from Dendroctonus, however analysis of the various SRAs from which this transcriptome is made shows that one of them (SRR2044898) contains in addition to Dendroctonus a second unidentified species from which this baratin precursor transcript originates].

\section{Calcitonin B}

The Leptinotarsa and one of the Anoplophora calcitonin genes encode not only typical calcitonin peptides, but also a number of structurally very similar peptides that lack the disulfide bridge in the N-terminal portion of the molecule (Fig. 4).

\section{Elevenin}

Like ACP, elevenin has been lost independently at least three times and in those species where this gene is still present the predicted elevenin sequences are also very variable (Fig. 5).

\section{Myosuppressin}

Myosuppressin is always located at the very end of its precursor and in virtually all insect species after the Gly residue that will be transformed in the C-terminal amide the precursors ends with two, three or occasionally four dibasic amino acid residues. Surprisingly this is not so in Coleoptera, where all myosuppressin precursors terminate with a few additional amino acid resiudes after those dibasic amino acid residues (Fig. S3).

\section{Orcokinin convertase cleavage sites}

In those species where the organization of the exons of the orcokinin gene could be established, it was similar to the one described previously for other insects (e.g. Veenstra \& Ida, 2014). Due to the presence of numerous copies of orcokinin B peptides, sequences of this gene are usually very difficult to assemble using short reads and this explains the problems with the orcokinin genes of Oryctes and Aleochara, although in both cases the presence of orcokinin was established. What makes these genes interesting is the convertase cleavage sites in the orcokinn B precursors. Proteolytic processing of neuropeptide from their precursors occurs at specific dibasic amino acid residues, usually a Lys-Arg pair. When processing occurs at singe Arg 
362 residues, as is the case for most orcokinin B precursors, empirical rules describe that other

363 dibasic amino acid residues need to be located nearby in the precursor (Veenstra, 2000).

364 However, orcokinin B precursors do not conform, which suggests that they are processed by a

365 different convertase than the one processing the majority of insect neuropeptide precursors.

366 Interestingly, in the two Coccinellids studied here, Harmonia and Coccinella, as well at least

367 another, Serangium japonicum (GGMU01110504.1), the convertase cleavage sites have been

368 replaced by the more classical Lys-Arg sites. In Aethina a few single Arg cleavage sites are still

369 present, but the majority are also Lys-Arg pairs (Fig. S4). This suggested that this second

370 convertase may have been lost. The two most common neuroendocrine convertases are PC1/3

371 and PC2; both are commonly present in insects (e.g. Veenstra, 2017), but PC1/3 is absent from

372 Drosophila, a species in which the orcokinin B precursor also has Lys-Arg convertase cleavage

373 sites (Veenstra and Ida, 2014). When looking for these two convertases in Coleoptera, it became

374 clear that PC1/3 is similarly lacking in Coccinellids but present in the other species, including the

375 Aethina.

376

377

378

379

380

381

382

383

384

385

386

387

388

389

390

391

392

393

394

395

396

397

\section{Periviscerokinin (Capa peptides)}

The periviscerokinins have often the typically the C-terminal sequence FPR(V/L/I)amide, but although some of the Coleoptera peptides have this sequence (Fig. S5), others have not. Detailed analysis of three receptors activated by pyrokinins, tryptopyrokinins and periviscerokinins in Tribolium shows that a periviscerokinin with a C-terminal LTPSLRVamide is as good a ligand as the MVSFPRIamide (Jiang et al., 2014). This analysis also reveals that none of these receptors preferentially recognizes the tryptopyrokinins, which in Drosophila and mosquitoes have a dedicated receptor (Cazzamali et al., 2005; Olsen et al., 2007). Unfortunately, I was unable to reconstruct a complete periviscerokinin transcript for neither Leptinotarsa nor Harmonia from either the genomic or the transcriptomic data.

\section{Proctolin}

The predicted proctolin sequences of Harmonia, Coccinella and Oryctes deviate from the classical peptide. This is described in more detail in the following section on gene losses.

\section{Gene Losses}

\section{Unambiguous gene losses}

There are a number of instances in which genes could not be found in the assembled genome of a species. In six cases this concerns neuropeptides with a known and unique receptor which is also absent from the same genomes that lack the genes for the ligands. It was previously reported that the Tribolium lacks both ligand and receptor genes for allatostatin A, corazonin and leucokinin (Li et al., 2008; Hauser et al., 2008). The first two were found to be absent from all Coleoptera studied here, while both leucokinin and its receptor were found in Pogonus, the only species outside the Polyphaga suborder for which a genome is available. However, neither 
398 leucokinin nor its receptor was found in any of the other species. Leucokinin is also present in

399 other species that do not belong to the Polyphaga suborder. As noted above both ACP and

400 elevenin were lost independently at least three times, while natalisin was lost at least twice in

401 Coleoptera (Fig. 6). Interestingly in Photinus there is still a remainder of the original calcitonin

402 gene. It is clearly defective as it misses essential parts and it is no longer expressed, while the

403 putative receptor ( $c f$ Veenstra, 2014) is completely gone. A similar situation occurs with the 404 relaxin gene in Sitophilus oryzae; there also a remainder of non-functional relaxin gene is still 405 present, but its putative receptor ( $c f$ Veenstra, 2014) is absent.

406

407

408

409

410

411

\section{2}

413

414

415

416

417

418

419

420

421

422

423

424

425

426

427

428

429

430

431

432

\section{Dilp8 orthologs}

The structure of dilp8, Drosophila insulin-like peptide 8 , is very poorly conserved and it has so far not been detected outside flies. LGR3 (Leucine Rich Repeat GPCR-3) has been identified as the receptor for this peptide (Vallejo et al., 2015) and this receptor, although absent from Tribolium, was found in a number of species (Fig. S7), suggesting that it got independently lost on at least four occasions (Fig. 6).

\section{Eclosion Hormone}

Most Coleoptera have two eclosion hormone genes (Fig. S8), but the second gene appears to be missing in Coccinella, Harmonia and Dendroctonus, while in Hycleus there is still a sequence that can be recognized as once have being part of such a gene, but it is probably no longer functional as (1) there are no expression data for the second gene, while such data is abundant for the first one, and (2) it seems to lack an essential intron donor site. In many genomes the two genes are located on the same contig. All four possible configurations [head to head, tail to tail, one upstream from two, two upstream from one] are present, but there is no clear pattern.

\section{Elevenin}

The presence of elevenin in Oryctes and Aleochara is not clear. On the one hand there are genomic sequences in Oryctes that code for what looks like parts of an elevenin precursor, even though the predicted elevenin peptide deviates even more from the elevenin consensus sequence than the average Coleopteran elevenin. On the other hand no traces were found of a putative elevenin GPCR. Therefore elevenin may well be also absent from Oryctes. A similar but different problem occurs with Aleochara, here a putative elevenin GPCR is present in the genome, but the elevenin precursor could not be found. This is not so surprising as its precursor is hardly conserved outside the sequence of the neuropeptide itself and even that sequence is so poorly conserved within the Coleoptera (Fig. 5) that the characteristic intron splice site inside the neuropeptide sequence is often needed to confirm that it is indeed elevenin. However, the same intron splice site makes finding homologous sequences much more difficult. 
433 sNPF

434 In all species an SNPF GPCR can be identified, but the sNPF precursor (Fig. S9) was

435 found in neither the Photinus nor the Aquatica genome. These two Coccinellid species are

436 relatively closely related and the absence of the sNPF precursor from both suggests that it was

437 already lost in their last common ancestor. It seems unlikely to be a case of genome assembly

438 problems, as despite several efforts not a single transcriptome read could be found that could

439 represent an sNPF mRNA. There are two possible explications. The first one is that the sNPF

440 precursor has been lost in these two species but its receptor is still being used by a different

441 peptide, e.g. another N-terminally extended RFamide. The second possibility is that the sequence

442 of the peptide has undergone so many structural changes, that it is now impossible to find it

443 using the BLAST program for homology searches.

444

445

446

447

448

449

450

451

452

453

454

455

456

457

458

459

460

461

462

463

464

465

466

467

468

469

470

\section{Proctolin}

Proctolin was the first neuropeptide for which a complete chemical structure was determined (Starratt \& Brown, 1975). It is commonly present in insects, although it seems to be absent from at least some Lepidoptera and Hymenoptera (e.g. Roller et al., 2008; Kanost et al., 2016; Hummon et al., 2006; Hauser et al., 2006, 2010; Schmitt et al., 2015). Its pentapeptide sequence (Arg-Tyr-Leu-Pro-Thr) has been well conserved during evolution and is exactly the same in Chelicerates, Myriapods, Decapods and insects (Veenstra, 2016a,c). It is therefore interesting to see that in Coccinellids the predicted sequence of this peptide has mutated to [Ser ${ }^{4}$-proctolin. In Oryctes the proctolin precursor also predicts a non-classical proctolin, in this case $\left[\mathrm{Ala}^{5}\right]$-proctolin. In all three species these sequences are deduced from both the genome and transcriptome sequences. On the other hand, the overall structures of these putative proctolin precursors are well conserved (Fig. S10). Nevertheless, no proctolin receptors could be found in either Oryctes or two Coccinelid species.

\section{Other peptides that are absent from Coleoptera}

Calcitonin A and CCRFamide have never been found in Holometabola, and they were neither found here. In Coleoptera tryptopyrokinin coding sequences were only found as part of the periviscerokinin and pyrokinin genes and hence a specific tryptopyrokinin gene as exists in termites and locusts (Veenstra, 2014) was not found in Coleoptera. Of the three allatostatins Cs (Veenstra, 2016b) only CC and CCC were found and neither did we find any evidence for a second NPF gene. EFLamide is difficult to find, because its conserved sequence is so short (Veenstra, 2019). Insect species that have an EFLamide gene also have an ortholog of the Platynereis EFLamide GPCR (Bauknecht \& Jékely, 2015), but such an ortholog is missing from all the Coleoptera genomes studied here.

The recently described putative neuropeptide precursor RFLamide (Liessem et al., 2018) is easily detectable in most Coleoptera (Fig. S11), but was not found in either of the two Curculionids, Hypothenemus and Dendroctonus. Hence, it is likely that this gene is missing from those two species as well as from other Curculionidae. 


\section{Gene Duplications}

$472 \mathrm{AKH}$

473 When the putative Coleopteran AKH precursors are aligned it is evident that they consist 474 of four different regions, the signal peptide, the $\mathrm{AKH}$ peptide sequence with its processing site 475 consisting of the GKR triplet, a hydrophilic connecting peptide (C-peptide) and a more 476 hydrophobic disulfide bridge containing sequence (Cys-peptide). It is noticeable that the 477 sequences of the signal peptides, AKHs and the Cys-peptides are very well conserved (Fig. 7), 478 albeit that there are a number of exceptions. The most glaring examples are the second putative 479 Harmonia AKH gene, which obviously can not encode an AKH, and the putative Aethina AKH 480 precursor that is predicted to have no functional signal peptide.

Bursicon

482

483

484

485

486

\section{CCHamide 2}

The bursicon sequences are all very similar, as expected from this well conserved and essential insect hormone (Figs. S12 and S13). Oryctes is the only species that is noteworthy in that it has two bursicon A genes the start ATGs of which are 4184 nucleotides apart on the same contig. When one compares the predicted mature protein sequences, it is clear that the second one has several amino acid changes which in all the other proteins are well conserved (Fig. S12). It is impossible to know which of these two genes are most expressed, as all the Bursicon A intron splice sites in both genes are ignored by the various RNAseq reads. The only Trinity transcript generated from this genomic region that has an intron reveals that it was generated from the opposite DNA strand. So possibly all the RNAseq reads present in the only public transcriptome SRA (SRR2970555) that cover the Bursicon A genomic region of this species are generated from the opposite strand and thus originate from a different gene.

\section{Calcitonin}

Two genes coding calcitonin B are present in Anoplophora, Hycleus, Tribolium and Tenebrio, they are described in greater detail in the section on paracopy duplication. receptor. One of the two CCHamide 2 gene codes for a typical CCHamide 2 neuropeptide, the second CCHamide 2 peptide lacks the typical C-terminal amide. Phylogenetic tree analysis of CCHamide receptors shows that the two Leptinotarsa CCHamide 1 receptors are more similar to one another than to the Anoplophora ortholog, thus suggesting that the duplication of this receptor is relatively recent (Fig. 8). 
503

504

505

506

507

508

509

510

511

512

513

514

515

516

517

518

519

520

521

522

523

524

525

526

527

528

529

530

531

532

533

534

535

536

537

538

539

\section{Insulin-related peptides}

Insects have three different types of insulin, two of which act, predominantly or exclusively, through GPCRs, these are relaxin and the dilp8 orthologs. The third type acts through a classical tyrosine kinase receptor and in most insect species the latter insulin genes are amplified. In Coleoptera their numbers range from two in Aquatica and Pogonus to ten in Anoplophora. The primary amino acid sequence is in general not very well conserved, making it difficult if not impossible to make reliable trees of insect insulin genes. However, it is clear that genes were lost and added on multiple occasions. The strong sequence divergence of these proteins implies that one can only make pylogenetic trees for relatively closely related species. Such a tree for Hycleus, Tribolium and Tenebrio (Fig. S15) shows that almost all of their insulin genes are direct orthologs from one another. A similar tree made for the insulin sequences from Dendroctonus, Hypothenemus, Anoplophora, Leptinotarsa and Aethina similarly shows shared ancestors for several of their insulin genes as well as recently amplified insulin genes in Leptinotarsa, Anoplophora and Aethina (Fig. S16).

\section{Myosuppressin}

In Leptinotarsa the myosuppressin gene has been amplified and its genome now has four such genes, one that is producing a classical myosuppressin and three others that at first sight seem to code for a smaller analog of myosuppressin, but on the basis of the described specificity of neuropeptide convertase (Veenstra, 2000), it is also possible that they produce N-terminally extended myosuppressins, as Lys-Arg cleavage sites followed by an aliphatic amino residue are rarely cleaved, and this even more unlikely for the precursor in which the putative Lys-Arg cleavage site has mutated into a Lys-Lys site (Fig. S3). All four genes are expressed as shown by the various RNAseq SRAs. Interestingly, this gene is also amplified in the Scarabaeid

Onthophagus taurus, where there are at least three genes that express a myosuppressin precursor. Thus the myosuppressin gene was amplified independently at least twice in Coleoptera.

\section{Neuroparsin}

The neuroparsin gene is present as a single copy in all species, except Oryctes where it is duplicated (Fig. S17) and perhaps even triplicated, as the second gene is present in two copies in the genome assembly; those may represent either two quite divergent alleles of the same gene or perhaps more likely a gene duplication. In the RNAseq SRA of this species (SRR2970555) these three sequences are represented by 44, 19 and 11 half spots respectively).

\section{Pyrokinin}

The basic beetle pyrokinin gene has three coding exons, the two introns in between are phase 1 and phase 0 , which makes amplification of the intermediate coding exon, such as occurred in the periviscerokinin gene, very difficult. The first coding exon contains the signal peptide, the second a copy of tryptopyrokinin and the last one three pyrokinin paracopies. The Pogonus gene has three coding exons, but the precursor only codes for two pyrokinin paracopies. 
540 The tryptopyrokinin has also been lost from the Coccinelid precursors, one of two pyrokinin 541 precursors in Nicrophorus, Dendroctonus, Hypothenemus, Anoplophora and Leptinotarsa, all 542 Photinus, Aquatica and Ignelater precursors and probably three out of five in Aethina. It thus 543 looks like that in several Coleoptera species evolution favored the production of pyrokinins over 544 that of tryptopyrokinin from these genes. The pyrokinin gene is amplified in five of the species 545 studied here; most of these are segmental amplifications, but in Oryctes there is one gene that has no longer any introns and may have originated from retroposition (Fig. S18).

547 Relaxin

The gene coding for relaxin (the ortholog of Drosophila insulin-like peptide 7) is duplicated in Aethina (Fig. S19). Both copies look like they can produce functional proteins and both genes are expressed (there are 170 and 89 reads for for the coding sequences of relaxin-1 and -2 respectively in SRR1798556).

Vasopressin

Genes encoding vasopressin-related peptides were found in all species analyzed (Fig. S20). In all of them, except Leptinotarsa, these genes code for CLITNCPRG-amide, the pepide that was identified from Locusta migratoria (Proux et al., 1987). In the Colorado potato beetle two such genes were found and they code for two different vasopressin-like molecules CLITNCPKG-amide and its analog CLITNCPIG-amide. Interestingly, various vasopressin antisera that were used to label vasopressin-immunoreactive neurons in this species labeled the two vasopressin-specific neurons only weakly while the adjacent pyrokinin containing neuroendocrine cells that have a C-terminal PRLamide sequence intensely (see e.g. fig. 3 from Veenstra, Romberg-Privee \& Schooneveld, 1984), while the same antisera stain the vasopressin specific cells in the Locusta just as intensely as the ones producing pyrokinin (Veenstra, 1984). Each of the two Leptinotarsa peptides could explain these results, the Lys-analog, as the Lys residue is likely to be cross-linked by formaldehyde and hence no longer immunoreactive, and the Ile-analog because it lacks the basic amino acid residue that is likely important for immunroeactivity. Counts of RNAseq reads in Leptinotarsa SRAs reveals twice as many reads for the Ile-analog as for the Lys-analog (652 versus 341).

Although there are two vasopressin genes, there is only a single vasopressin receptor present in the genome.

\section{Exon duplications}

571

572

573

574

Allatostatin CCC

In both Aleochara and Nicrophorus, but not in closely related Oryctes, the second and last coding exon of the allatostatin CCC gene has been duplicated allowing the production of two different allatostatin CCC transcripts (Fig. 9) predicted to produce slightly different allatostatin 
575 CCC peptides that both conform to the consensus sequence of this peptide (Veenstra, 2016b). In

576 the other species only a single allatostatin CCC precursor was found (Fig. S21).

577

578

579

580

581

582

583

584

585

586

587

588

589

590

591

592

593

594

595

596

597

598

599

600

601

602

603

604

605

606

607

608

609

610

\section{Allatotropin}

The Pogonus allatotropin precursor is almost indistinguishable from the Hemimetabola sequences; it shares with them the N-terminal Gly-Phe-Lys and the remainder of its precursor is also very similar. However, in the other Coleoptera allatotropin sequences these characteristics have not been conserved (Fig. S22). On two occasions the allatotropin precursor has acquired a second allatotropin paracopy, once by adding a second exon and a second time by adding an additional allatotropin paracopy directly next to the existing one (Fig. 10).

\section{Calcitonin}

The calcitonin precursor is one of the most variable neuropeptide precursors in Coleoptera (Fig. S23). A functional calcitonin gene is absent from Photinus, where a remainder of the gene for the peptide can still be found, but where the putative receptor has completely disappeared, while in four of the other species, Anoplophora, Hycleus, Tribolium and Tenebrio, there are two calcitonin genes. The Leptinotarsa and one of the Anoplophora genes encode not only typical calcitonin peptides, but also a number of structurally very similar peptides that lack the disulfide bridge in the $\mathrm{N}$-terminal portion of the molecule (Fig. 5). The number of paracopies predicted from each precursor varies from one to seven. The sequences of several of these precursors suggests that they have lost one or more calcitonin paracopies during evolution (Fig. S23).

$\mathrm{DH} 31$

The DH31 gene shows considerable variation in its structure and the peptides it produces. Although in all species, it codes for the classical DH31 that is very well conserved (Fig. S24), in several species additional neuropeptides are encoded on alternatively spliced mRNAs that do not encode DH31. In its most basic form the gene produces a single transcript from three coding exons containing respectively the signal peptide, a conserved peptide that does not look like a neuropeptide, and DH31. In several species, one or two coding exons that code for alternative neuropeptides have been inserted between coding exons for the conserved peptide and DH31. This leads to alternative splicing in which different neuropeptides are produced (Fig. 11). In Hycleus, Tenebrio and Tribolium at least three different mRNAs are produced enabling precursors sharing the same $\mathrm{N}$-terminal sequence but that have different $\mathrm{C}$-termini encoding an Arg-amide, a short Pro-amide and the typical DH31 peptide respectively. In contrast to DH31 itself, that has a very well conserved amino acid sequence, these alternative DH31 gene products lack well defined consensus sequences and are neither very similar to DH31 (Fig. S25).

In Pogonus there are two additional exons predicted from the trinity assembly of RNAseq sequences (Fig. 11). In two other Adephaga species, i.e. Gyrinus marinus and Carabus 
611 granulatus the transcriptome assembly sequences corresponding to DH31 sequences lack

612 sequences homologous to those two exons (GAUY02019591.1; GACW01024447.1).

\section{DH37-DH47 or CRF-like diuretic hormones}

614 The Tribolium DH37-47 gene has previously been reported to have three coding exons

615 (Li et al., 2008), in which the first of those three is alternatively spliced to the second or the third

616 one. This leads to the production of two CRF-like diuretic hormones, DH37 and DH47 which

617 both been isolated and sequenced from Tenebrio, a species of the same family. Given the

618 sequence similarity of DH47 (Fig. S26) and DH37 (Fig. S27) it seems likely that the last two

619 exons arose by exon duplication. This gene structure seems to be common to the Cucujiformia,

620 but in the other Polyphaga and Pogonus there are only two coding exons in which the last codes

621 for a CRF-like hormone. In Aethina the DH37 coding exon has been duplicated once more, such

622 that there are four coding exons in total and three different mRNAs are produced, each encoding

623 different CRF-like peptides (Fig. 12).

624

625

626

627

628

629

630

631

632

633

634

635

636

637

638

639

640

641

642

643

644

645

646

647

\section{Periviscerokinin (Capa)}

The periviscerokinin genes are quite variable in Coleoptera. They can consist of several coding exons that all use phase 1 introns. This allows alternative splicing to produce a variety of different precursors from these genes. Although in some species RNAseq data confirm such alternative splicing, in many cases the number of total RNAseq reads for these genes is far too small to demonstrate alternative splicing. An important site of periviscerokinin synthesis is in the abdominal ganglia, from which RNAseq reads are generally only obtained when whole insects are used for RNA extraction. Thus while in many species only a single transcript can be documented, alternative splicing may well be common.

The number of coding exons for this gene in the species studied varies between four and seven (Fig. 13). The first coding exon contains the sequence for the signal peptide, the last for a hydrophilic C-terminal sequence of the precursor that is usually rich in acidic amino acid residues. The penultimate coding exon tends to be the largest and codes for subsequently a periviscerokinin, a tryptopyrokinin and a hydrophobic sequence. The variable number, one to four exons between the first and pentultimate coding exon, contain sequences for a pyrokininlike peptide, although in Hypothenemus, the third one has lost this sequence.

\section{SNPF}

The sNPF precursor is very well conserved in Coleoptera (Fig. S9). In Anoplophora and Leptinotarsa, but not in closely related Dendroctonus and Hypothenemus or any of the other species studied here, partial duplication of the exon coding SNPF led to a gene having an additional coding exon. In Anoplophora the RNAseq data suggest the production of two alternatively spliced transcripts that code for either one or two SNPF paracopies. Although there is much more RNAseq data from Leptinotarsa, in this species there is only evidence for a single mRNA encoding two sNFP paracopies (Fig. 14). 


\section{Paracopy numbers}

649 Several insect neuropeptide precursors contain multiple copies of identical or very similar 650 peptides. These typically include allatostatins $\mathrm{A}$ and $\mathrm{B}$, calcitonin $\mathrm{B}$, leucokinin, FMRFamide, 651 pyrokinin, periviscerokinin, ETH, orcokinin A and B, RYamide, sulfakinin and tachykinins. The 652 number of such paracopies can vary between and even within species (e.g. Veenstra, 2010). The 653 genes coding calcitonin $\mathrm{B}$, leucokinin, pyrokinin and periviscerokinin have already been 654 discussed above. Allatostatin A has so far never been found in Coleoptera. ETH has usually two 655 paracopies, but in the three species from the Elateroidea, i.e. Ignelater, Photinus and Aquatica, 656 the first copy has been lost (Fig. S28) and this is also the case in Aleochara and Hypothenemus.

657 In all five of these species, the genome still contains coding sequences for both splice variants of 658 the ETH receptor. The RYamide gene codes for two RYamide peptides in all Coleoptera (Fig. 659 S29), except Anoplophora that lost this gene and its receptor, while the sulfakinin gene codes also for two paracopies in all species studied here (Fig S30). The number of FMRFamide paracopies varies from four to six (Fig. S31), and from 5 to 9 NPLP1 precursor (Fig. S32) and for allatostatin B (Fig. S33) the numbers are from seven for the Curcuclionids Dendroctonus and Hypothenemus to eight for the other species.

664

665

666

667

668

669

670

671

672

\section{3}

674

675

676

677

678

679

680

681

682

683

684

\section{Tachykinin}

The calcitonin B and tachykinin genes are those that show significant changes in the number of neuropeptides encoded. The ancestral tachykinin gene in Coleoptera likely coded for eight paracopies, the number found in the majority of species. Oryctes and Harmonia each lost one paracopy, but in Anoplophora there are only five paracopies and in Leptinotarsa there are just two left. In the latter species, the well conserved N-terminus of the precursor has also disappeared. This may well be a general phenomenon in Chrysomelidae as the transcriptome from Oreina cacaliae (GDPL01001642.1) reveals a very similar sequence (Fig. S34). Leptinotarsa does have an ortholog of the tachykinin receptor gene that looks normal.

\section{Genes that seem very stable}

It is fair to state that the number of changes in neuropeptide genes in Coleoptera is significant. This might obscure the fact that many other genes seem, as least as far as their sequences are concerned, remarkably stable, such is the case for CCAP (Fig. S35), SIFamide (Fig. S36), Sulfakinin (Fig. S30), GPA2 (Fig. S37), GPB5 (Fig. S38), FMRFamide, (Fig. S31) hansolin ( Fig. S39; Liessem et al., 2018), CNMamide (Fig. S40), ITG (Fig. S41) and PTTH (Fig. S42). The mRNA from the gene coding ion transport peptide (ITP) is generally alternatively spliced in two froms, ITP-A (Fig. S43) and ITP-B (Fig. S44). It has been reported that in Tribolium there is a third splice product (Begum et al., 2008), but such a form could not be detected for any of the other species studied here, including Hycleus or Tenebrio, two species closely related to Tenebrio. 


\section{Discussion}

686 A previous study on neuropeptides in twelve Drosophila species found their

687

688

689

690

691

692

693

694

695

696

697

698

699

700

701

702

703

704

705

706

707

708

709

neuropeptidomes to be remarkably similar (Wegener \& Gorbashov 2008). This is the first time that the neuropeptidomes of several species of the same insect order that are not as closely related have been compared. The results clearly show considerable variation within Coleoptera, variation that seems to be almost as large as that seen between species from different orders. By using a variety of species some surprising findings, such as e.g. the very evolved structures of NPF and PDF or the loss of certain neuropeptide genes, are confirmed in related species, and they can thus not be attributed to experimental error.

In the same way that there are differences between the different neuropeptides, there are also differences between the different species. Leptinotarsa is perhaps the species in which the neuropeptidome has evolved the most. It has two vasopressin genes, its allatotropin and SNPF genes encode two paracopies each, it lost both elevenin and ACP and it duplicated the CCHamide 1 receptor and CCHamide 2 neuropeptide genes. Anoplophora is another member of the Chrysomeloidea superfamily with a neuropeptidome with significant changes. Although Anoplophora still has elevenin and ACP, it lost RYamide and it has a large number of insulin genes. Both these species are specialist herbivores, like many Cucujiformia. Always eating the same or almost the same food might eliminate some physiological uncertainties that no longer need to be regulated. Variation in protein, carbohydrate and water content in food should be much more limited in specialists than in generalists. For example, if RYamide is indeed an antidiuretic hormone as suggested (Veenstra and Khammassi, 2016) it might become obsolete in a species that is always exposed to the necessity to conserve water. It will no longer be necessary to increase water conservation during times of water shortage and decrease it when the insect is fully hydrated and thus there may be no longer a need for the acute regulation of antidiuresis; it always has to be optimal.

\section{Significant peptide sequence changes}

In those Coleoptera where elevenin and ACP are (still) present neither the sequences of the peptides nor of those of their precursors are well conserved. Other neuropeptides have not only maintained the sequences of the neuropeptides themselves, but often those of the entire precursors, suggesting that those parts of the precursor that do not code for the biologically active peptides must have other important functions. It has previously been noted that as expression of the RYamide gene in Drosophila species decreases, the structure of both the neuropeptides themselves and their precursors are no longer well conserved (Veenstra and Khammassi, 2016). This could mean that the function of the peptide is becoming obsolete, which would facilitate its subsequent loss; use it or loose it. However, it is also possible that it is no longer needed in the large quantities that are necessary for discharge into the hemolymph. This might well be the case for Drosophila RYamide where the rectal papillae in D. melanogaster are innervated by RYamide neurons. While the same neurons are present in $D$. virilis, in that species - and many others - RYamide is also released from enteroendocrine cells, presumably likewise 
724 to stimulate the rectal papillae. The amount of RYamide that needs to be released from the

725

726

727

728

729

730

731

732

733

734

735

736

737

738

739

740

741

742

743

744

745

746

747

748

749

750

751

752

753

754

755

756

757

758

759

760 midgut to reach sufficiently high hemolymph concentrations will be much larger than that made by the neurons that directly innervate the rectal papillae. This likely not only puts selection pressure on the peptide sequences but also on an efficient processing of their precursors. It is the latter that may explain why some insect neuropeptide precursors seem to be so well conserved.

In Rhodnius and Tribolium ACP appears to be expressed exclusively in neurons (Hansen et al., 2010; Patel et al., 2013). This suggests that its large structural variability indicates a loss of physiological relevance in Coleoptera which may explain its loss from the genome on at least three occasions in this insect order. The same could also be true also for elevenin and it is tempting to speculate that when neuropeptide structures are no longer well conserved it either indicates the loss of their physiological relevance as a hormone or as both a hormone and a neuromodulator. For small neuropeptides that act on GPCRs replacement of a single critical amino acid may be enough to impair receptor binding. Insulin is larger and needs to bind simultaneously to two tyrosine kinases it may therefore be less sensitive to single amino residue replacements as long as the three dimensional structure of the molecule is maintained and interaction with its receptor is still possible.

It is interesting to see that some changes in Coleoptera neuropeptide precursors are similar to the those observed in other Holometabola. The allatotropin genes in Hemimetabola code for a single allatotropin paracopy, but in Lepidoptera the gene encodes various allatotropinlike peptides produced on alternatively spliced mRNAs (e.g. Taylor, Bhatt \& Horodyski, 1996; Nagata et al., 2012). Whereas, the Pogonus allatotropin gene is quite similar to those of the Hemimetabola, in the Polyphaga suborder allatotropin genes coding for two paracopies emerged on two occasions. The sNPF gene in Hemimetabola is also very simple, but in Lepidoptera and Diptera, the gene codes for several paracopies. Again this evolved independently in Anoplophora and Leptinotarsa. If proctolin is indeed absent from Oryctes and the Coccinellids, this would be similar to what occurred in Hymenoptera and Lepidoptera. Thus in at least some cases neuropeptide evolution in different holometabolous insect orders seems to follow what look to be similar pathways, i.e. increasing paracopies in neuropeptide genes that look like they never changed from the ancestral arthropod to cockroaches, decapods and chelicerates, or independently eliminating others, such as elevenin and ACP. This raises the question whether somehow complete metamorphosis is responsible for these changes.

Several neuropeptides contain a cysteine bridge structure constraining the structure of the peptide. This could have important effects on receptor binding and/or provide it protection against proteases degradation. It is surprising to see NPF gain a cysteine bridge in the Cucujiformia and some, but not all, calcitonins in Leptinotarsa and Anoplophora loose theirs. It would be very interesting to see the interactions of these peptides with their receptors in order to know what effects, if any, these structures have on receptor activation. 
761

762

763

764

765

766

767

768

769

770

771

772

773

774

775

776

777

778

779

780

781

782

783

784

785

786

787

788

789

790

791

792

793

794

795

796

797

798

799

800

\section{Gene losses}

It appears that loss of a neuropeptide sytems is not a very rare event and some neuropeptides are more easily eliminated than others. Thus, in Coleoptera some neuropeptides got lost repeatedly, i.e. elevenin and ACP each at least three times, natalisin twice and the dilp8 ortholog likely four times. Indeed, elevenin, ACP, calcitonin, corazonin, natalisin, dilp8 and relaxin were also found missing in other insect species (e.g. Huybrechts et al., 2010; Veenstra, 2014; Veenstra, 2019).

Although the loss of a neuropeptide signaling system may well have its origin in the degeneration of the peptide gene, for the reasons of gene sizes, it is as likely to start in the receptor gene. Not only are the receptor coding regions generally much larger than those of neuropeptides, but more often than not the total size of these genes is enormous. Thus the accidental elimination of a large piece of DNA after chromosome breakage and rearrangement may well be limited to sequences coding a receptor without altering any adjacent genes, while the elimination of a piece of the same size that touches a neuropeptide gene is more likely to affect also neighboring genes, thus increasing the likelihood of selection against such an event. Indeed in at least some instances, one can still find remnants of the ligand gene, while the receptor has vanished. Apart from calcitonin B in Photinus described here, the same phenomenon is observed with relaxin in Sitophilus and sulfakinin in the tsetse fly Glossina morsitans. In the latter species a highly degraded sulfakinin pseudogene is still recognizable, while both sulfakinin receptor genes have been lost (BLAST Data).

As discussed above if the sequence of a neuropeptide is no longer maintained it may indicate the loss of physiological relevance. This might be a useful criterium to look at duplicated neuropeptide genes as well. When the putative Coleopteran AKH precursors are compared it is evident that not all these precursors are well conserved. If the bulk of AKH precursor sequences is so well conserved, why are the others not? We have a good idea about what signal peptides and authentic AKHs should look like, and we can thus discard the truly aberrant genes from Aethina and Harmonia as obviously no longer functional AKH genes (Fig. 7). However, we do not know what the requirements are for a good Cys-peptide, as its function is unknown. Similar Cys-peptides have been found in other insect neuropeptide precursors, such as those of SIFamide and RYamide (Verleyen, Huybrechts \& Schoofs, 2009; Veenstra \& Khammassi, 2017). The conservation of the structure of such peptides implies that they are important - perhaps for assuring correct intracellular transport to the secretory granules of the neuropeptide precursors - and thus that those precursors that no longer have such a conserved Cys-peptide may be functionally impaired. Predicted AKH precursors that look like they might be defective are only found in species that also have an AKH gene with a well conserved AKH precursor. This suggests that AKH precursors that are not well conserved may have largely lost their functional significance and/or may be evolving into pseudogenes. It is interesting in this context that of the two Tribolium AKHs only the one that has the best conserved precursor sequence could be detected by mass spectrometry (Li et al., 2008). Similar arguments suggests that the copy of the Oryctes Bursicon A gene may well be on its way to become a pseudogene. 
801

802

803

804

805

806

807

808

809

810

811

812

813

814

815

816

817

818

819

820

821

822

823

824

825

826

827

828

829

830

831

832

833

834

835

836

837

838

839

The predicted signal peptides of the proctolin precursors from Oryctes, Harmonia and Coccinella seem to be perfectly normal as do other parts of the precursor that have been conserved since the last common ancestor of chelicerates and mandibulates. However, the predicted proctolin molecules have been mutated and these species all seem to have lost their proctolin receptors. It is a very puzzling and unresolved matter; as if proctolin is not the only biologically active peptide produced from the proctolin precursor or as if there is yet another proctolin receptor that remains to be identified.

\section{Gene duplications}

Gene duplications are a common phenomenon during evolution and most of these duplicated genes are subsequently lost (Lynch, 2007). Genes coding insulin-related peptides and adipokinetic hormones are repeatedly amplified in insects and in Coleoptera this also includes pyrokinin genes. Why is it that some neuropeptide genes regularly show increased numbers while others do so only rarely? When there are paralogous genes in a genome, this is the result of two independent processes, first duplication of the original gene and then maintaining both the original and its copy.

Just like elimination of receptor gene is likely facilitated by its large size, the initial duplication of a neuropeptide gene is probably more easily accomplished due to the smaller the sizes of the gene. It is striking in this context that both the insect AKH and insulin genes - two that are commonly amplified in insects - are generally very compact genes, have small introns and plausibly small regulatory regions (of that we only have some information from Drosophila, which is not necessarily a model for all insect species). The Coleoptera pyrokinin genes similarly look very compact, as the sizes of the introns between the coding regions are small. This is also true for the strongly amplified vasopressin genes in Locusta (Veenstra, 2014).

Such small sizes may not only favor the original duplication, but also make it much more difficult to eliminate the gene by gross chromosome reorganizations and this may explain the presence of amplified genes in a genome that are not as well conserved as others. However, in order to permanently maintain two paralog genes, there also needs to be an advantage to maintaining both copies. This is often achieved through neo- or subspecialization (Lynch, 2007). In Drosophila the different insulin genes do not all have the same temporal and spatial expression (e.g. Brogiolo et al., 2001; Liu et al., 2016), suggesting that subspecialization may be at least part of the reason these genes are maintained. I have previously suggested that in some cases it may be the need for massive amounts of neuropeptides that facilitates the maintenance of paralog neuropeptide genes (Veenstra, 2014). In the case of the Coleoptera pyrokinin genes this may well apply also, but there is maybe something else at play as well.

Pyrokinins, tryptopyrokinins and periviscerokinins are structurally similar arthropod peptides that each act on specific receptors (Iversen et al., 2002; Rosenkilde et al., 2003; Cazzamali et al., 2005; Homma et al., 2006; Paluzzi et al., 2010; Paluzzi and O'Donnell, 2012;

PeerJ reviewing PDF | (2019:02:35410:1:1:NEW 24 Apr 2019) 
840 Jiang et al., 2014). The tryptopyrokinins are only present in insects, where they seem to play an 841 important physiological role and they are absent from basal arthropods. In most insect species

842 they are coded by two different genes, the pyrokinin and periviscerokinin genes. The pyrokinin

843 genes codes for pyrokinins, often also for a tryptopyrokinin and rarely even a periviscerokinin.

844 The periviscerokinin gene codes for periviscerokinins, often a tryptopyrokinin and rarely a

845 pyrokinin. What ever their exact roles or physiological functions, there appears to be a

846 physiological need to be able to produce these three types of peptides, pyrokinins,

847 tryptopyrokinins and periviscerokinins independently from one another. In termites, crickets,

848 stick insects, locusts and cockroaches separate tryptopyrokinin genes have evolved that code for

849 a tryptopyrokinin precursors containing multiple tryptopyrokinins. However, this has not

850 happened in holometabolous insects.

851 The tryptopyrokinins are produced predominantly, if not exclusively, by neuroendocrine

852 cells in the labial neuromere of the suboesophageal ganglion from either a pyrokinin or

853 periviscerokinin precursor by mechanisms that are not understood. Although receptor ligand

854 interactions in Tribolium suggests that at least in that species there may be no tryptopyrokinin

855 specific receptor (Jiang et al., 2014), in the closely related Zoophobas atratus the

856 periviscerokinin precursor is still differentially processed to produce predominantly a

857 tryptopyrokinin and pyrokinin in the suboesophageal ganglion and periviscerokinins in the

858 abdominal ganglia (Neupert et al., 2018). Interestingly, in Tribolium the tryptopyrokinin from the

859 pyrokinin precursor is less active on the pyrokinin receptors than the one from the

860 periviscerokinin precursor (Jiang et al., 2014) and so it maybe no coincidence that the

861 tryptopyrokinin from was lost from a number of Coleoptera pyrokinin genes.

862 Whereas the pyrokinin genes are often amplified in Coleoptera, the periviscerokinin

863 genes are often sometimes partially amplified, i.e. a periviscerokinin coding exon is duplicated.

864 Adding an extra exon does not change the reading frame, since the introns defining the

865 duplicated exons are of the same phase. This makes alternative splicing relatively easy.

866 Duplication of this exon may be further facilitated by the presence of much larger introns than

867 those that are found in the pyrokinin gene.

868 The size of receptor genes should make their segmental duplication a relatively rare

869 event. It thus interesting that in Leptinotarsa the CCHamide 1 receptor is duplicated and that

870 both copies seem to be well expressed. Surprising and unexpected is that in the same species the

871 CCHamide 2 neuropeptide gene is also duplicated. Although this does not constitute final proof

872 for the evolution of a novel insect neuropeptide system in Leptinotarsa, it certainly is as close as

873 one can get from sequence data alone. Both receptor and peptide have evolved significantly since

874 their respective duplications (Fig. 8) and this very much suggests that Leptinotarsa has three

875 separate CCHamide neuropeptide systems.

876

877

878

879

\section{Conclusion}

Beetle species show very significant differences in their neuropeptidomes. Thus neuropeptidome variation may be (almost) as big within insect orders as it is between them. 
881

882

883

884

885

886

887

888

889

890

891

892

893

894

895

896

897

898

899

900

901

902

903

904

905

906

907

908

909

910

911

912

913

914

915

916

917

918

919

920

921

922

923

924

\section{Acknowledgements}

There is only single author on this publication, but obviously I have only done the easy part, i.e. using the excellent computer programs written by others to look at the very large amount of data collected and analyzed by many colleagues. To all of those who made this possible I express my most sincere gratitude.

\section{References}

Ando T, Matsuda T, Goto K, Hara K, Ito A, Hirata J, Yatomi J, Kajitani R, Okuno M, Yamaguchi K, Kobayashi M, Takano T, Minakuchi Y, Seki M, Suzuki Y, Yano K, Itoh T, Shigenobu S, Toyoda A, Niimi T. 2018. Repeated inversions within a pannier intron drive diversification of intraspecific colour patterns of ladybird beetles. Nature Communications 2018 9:3843. doi: 10.1038/s41467-018-06116-1.

Bauknecht P, Jékely G. 2015. Large-scale combinatorial deorphanization of Platynereis neuropeptide GPCRs. Cell Reports 12:684-693. doi: 10.1016/j.celrep.2015.06.052.

Begum K, Li B, Beeman RW, Park Y. 2009. Functions of ion transport peptide and ion transport peptide-like in the red flour beetle Tribolium castaneum. Insect Biochemistry and Molecular Biolology 39:717-725. doi: 10.1016/j.ibmb.2009.08.005.

Brogiolo W, Stocker H, Ikeya T, Rintelen F, Fernandez R, Hafen E. 2001. An evolutionarily conserved function of the Drosophila insulin receptor and insulin-like peptides in growth control. Current Biology 11:213-221. doi: 10.1016/S0960-9822(01)00068-9.

Cazzamali G, Torp M, Hauser F, Williamson M, Grimmelikhuijzen CJP. 2005. The Drosophila gene CG9918 codes for a pyrokinin-1 receptor. Biochemical and Biophysical Research Communications 335:14-9. doi: 10.1016/j.bbrc.2005.07.038.

Cunningham CB, Ji L, Wiberg RA, Shelton J, McKinney EC, Parker DJ, Meagher RB, Benowitz KM, Roy-Zokan EM, Ritchie MG, Brown SJ, Schmitz RJ, Moore AJ. 2015. The Genome and Methylome of a Beetle with Complex Social Behavior, Nicrophorus vespilloides (Coleoptera: Silphidae). Genome Biology and Evolution 7:3383-3396. doi: 10.1093/gbe/evv194.

Eigenheer RA, Nicolson SW, Schegg KM, Hull JJ, Schooley DA. 2002. Identification of a potent antidiuretic factor acting on beetle Malpighian tubules. Proceedings of the National Academy of Sciences of the United States of America. 99:84-89. doi: org/10.1073/pnas.012436199.

Elphick MR, Mirabeau O, Larhammar D. 2018. Evolution of neuropeptide signalling systems. Journal of experimental Biology 221. pii: jeb151092. doi: 10.1242/jeb.151092.

Fallon TR, Lower SE, Chang CH, Bessho-Uehara M, Martin GJ, Bewick AJ, Behringer M, Debat HJ, Wong I, Day JC, Suvorov A, Silva CJ, Stanger-Hall KF, Hall DW, Schmitz RJ, Nelson DR, Lewis SM, Shigenobu S, Bybee SM, Larracuente AM, Oba Y, Weng JK. 2018. 
925 Firefly genomes illuminate parallel origins of bioluminescence in beetles. Elife 7 pii: e36495.

926 doi: 10.7554/eLife.36495.

927

928

929

Furuya K, Schegg KM, Wang H, King DS, Schooley DA. 1995. Isolation and identification of a diuretic hormone from the mealworm Tenebrio molitor. Proceedings of the National Academy of Sciences of the United States of America 92:12323-12327. doi: org/10.1073/pnas.92.26.12323.

931

932

933

Furuya K, Schegg KM, Schooley DA. 1998. Isolation and identification of a second diuretic hormone from Tenebrio molitor. Peptides 19:619-626. doi: 10.1016/S0196-9781(97)00475-0.

934

935

Gäde G, Kellner R. 1989. The metabolic neuropeptides of the corpus cardiacum from the potato

936 beetle and the American cockroach are identical. Peptides 10:1287-1289. doi: 10.1016/0196-

937

938

939 9781(89)90023-5

Gäde G, Rosiński G. 1990. The primary structure of the hypertrehalosemic neuropeptide from tenebrionid beetles: a novel member of the AKH/RPCH family. Peptides 11:455-459. doi:

941

942

943

944 10.1016/0196-9781(90)90042-4.

Gäde G, Šimek P, Marco HG, 2015. Two novel tyrosine-containing peptides $\left(\mathrm{Tyr}^{4}\right.$ ) of the adipokinetic hormone family in beetles of the families Coccinellidae and Silphidae. Amino Acids.

945

946

947

948

949 doi: 10.1007/s00726-015-2011-4.

Gautier M, Yamaguchi J, Foucaud J, Loiseau A, Ausset A, Facon B, Gschloessl B, Lagnel J, Loire E, Parrinello H, Severac D, Lopez-Roques C, Donnadieu C, Manno M, Berges H, Gharbi K, Lawson-Handley L, Zang LS, Vogel H, Estoup A, Prud'homme B. 2018. The genomic basis of color pattern polymorphism in the Harlequin ladybird. Current Biology 28:3296-3302. doi:

951 10.1016/j.cub.2018.08.023.

952

953

954

Gouy M., Guindon S., Gascuel O. (2010) SeaView version 4 : a multiplatform graphical user interface for sequence alignment and phylogenetic tree building. Molecular Biology and

955

956

957

958

959 Evolution 27:221-224. doi: 10.1093/molbev/msp259.

Grabherr MG, Haas BJ, Yassour M, Levin JZ, Thompson DA, Amit I, Adiconis X, Fan L, Raychowdhury R, Zeng Q, Chen Z, Mauceli E, Hacohen N, Gnirke A, Rhind N, di Palma F, Birren BW, Nusbaum C, Lindblad-Toh K, Friedman N, Regev A. 2011. Full-length

960 transcriptome assembly from RNA-Seq data without a reference genome. Nature Biotechnology 961 29:644-52. doi: 10.1038/nbt.1883.

962

963

964

Hansen KK, Stafflinger E, Schneider M, Hauser F, Cazzamali G, Williamson M, Kollmann M, Schachtner J, Grimmelikhuijzen CJP. 2010. Discovery of a novel insect neuropeptide signaling

965

966

967

968 system closely related to the insect adipokinetic hormone and corazonin hormonal systems. Journal of Biological Chemistry 285:10736-10747. doi: 10.1074/jbc.M109.045369.

969

Hansen KK, Hauser F, Williamson M, Weber SB, Grimmelikhuijzen CJP. 2011. The Drosophila genes CG14593 and CG30106 code for G-protein-coupled receptors specifically activated by the 
970 neuropeptides CCHamide-1 and CCHamide-2. Biochemical and Biophysical Research

971 Communications 404:184-189. doi: 10.1016/j.bbrc.2010.11.089.

972

973 Homma T, Watanabe K, Tsurumaru S, Kataoka H, Imai K, Kamba M, Niimi T, Yamashita O,

974 Yaginuma T. 2006. G protein-coupled receptor for diapause hormone, an inducer of Bombyx

975 embryonic diapause. Biochemical and Biophysical Research Communications 344:386-393. doi:

976 10.1016/j.bbrc.2006.03.085.

977

978

979

980

981

982

983

984

985

986

987

988

989

990

991

992

993

994

995

996

997

998

999

1000

1001

1002

1003

1004

1005

1006

1007

1008

1009

1010

1011

1012

1013

1014

Hauser F, Cazzamali G, Williamson M, Blenau W, Grimmelikhuijzen CJP. 2006. A review of neurohormone GPCRs present in the fruitfly Drosophila melanogaster and the honey bee Apis mellifera. Progress in Neurobiology 2006 80:1-19. doi: org/10.1016/j.pneurobio.2006.07.005.

Hauser F, Cazzamali G, Williamson M, Park Y, Li B, Tanaka Y, Predel R, Neupert S, Schachtner J, Verleyen P, Grimmelikhuijzen CJP. 2008. A genome-wide inventory of neurohormone GPCRs in the red flour beetle Tribolium castaneum. Frontiers in Neuroendocrinology 29:142-165. doi: 10.1016/j.yfrne.2007.10.003.

Hauser F, Neupert S, Williamson M, Predel R, Tanaka Y, Grimmelikhuijzen CJP. 2010.Genomics and peptidomics of neuropeptides and protein hormones present in the parasitic wasp Nasonia vitripennis. Journal of Proteome Research 9:5296-5310. doi: 10.1021/pr100570j.

Hummon AB, Richmond TA, Verleyen P, Baggerman G, Huybrechts J, Ewing MA, Vierstraete E, Rodriguez-Zas SL, Schoofs L, Robinson GE, Sweedler JV. 2006. From the genome to the proteome: uncovering peptides in the Apis brain. Science 314:647-649. doi: $10.1126 /$ science. 1124128 .

Huybrechts J, Bonhomme J, Minoli S, Prunier-Leterme N, Dombrovsky A, Abdel-Latief M, Robichon A, Veenstra JA, Tagu D. 2010. Neuropeptide and neurohormone precursors in the pea aphid, Acyrthosiphon pisum. Insect Molecular Biology Suppl 2:87-95. doi: 10.1111/j.13652583.2009.00951.x.

Ida T, Takahashi T, Tominaga H, Sato T, Sano H, Kume K, Ozaki M, Hiraguchi T, Shiotani H, Terajima S, Nakamura Y, Mori K, Yoshida M, Kato J, Murakami N, Miyazato M, Kangawa K, Kojima M. 2012. Isolation of the bioactive peptides CCHamide-1 and CCHamide-2 from Drosophila and their putative role in appetite regulation as ligands for $\mathrm{G}$ protein-coupled receptors. Frontiers in Endocrinology 3:177. doi: 10.3389/fendo.2012.00177.

Iversen A, Cazzamali G, Williamson M, Hauser F, Grimmelikhuijzen CJP. 2002. Molecular cloning and functional expression of a Drosophila receptor for the neuropeptides capa-1 and -2. Biochemical and Biophysical Research Communications 299:628-633. doi: 10.1016/S0006291X(02)02709-2.

Jiang H, Wei Z, Nachman RJ, Adams ME, Park Y.2014. Functional phylogenetics reveals contributions of pleiotropic peptide action to ligand-receptor coevolution. Scientific Reports 4:6800. doi: 10.1038/srep06800. 
1016 Kanost MR, Arrese EL, Cao X, Chen YR, Chellapilla S, Goldsmith MR, Grosse-Wilde E, 1017 Heckel DG, Herndon N, Jiang H, Papanicolaou A, Qu J, Soulages JL, Vogel H, Walters J, 1018 Waterhouse RM, Ahn SJ, Almeida FC, An C, Aqrawi P, Bretschneider A, Bryant WB, Bucks S, 1019 Chao H, Chevignon G, Christen JM, Clarke DF, Dittmer NT, Ferguson LCF, Garavelou S, 1020 Gordon KHJ, Gunaratna RT, Han Y, Hauser F, He Y, Heidel-Fischer H, Hirsh A, Hu Y, Jiang H, 1021 Kalra D, Klinner C, König C, Kovar C, Kroll AR, Kuwar SS, Lee SL, Lehman R, Li K, Li Z, 1022 Liang H, Lovelace S, Lu Z, Mansfield JH, McCulloch KJ, Mathew T, Morton B, Muzny DM, 1023 Neunemann D, Ongeri F, Pauchet Y, Pu LL, Pyrousis I, Rao XJ, Redding A, Roesel C, Sanchez1024 Gracia A, Schaack S, Shukla A, Tetreau G, Wang Y, Xiong GH, Traut W, Walsh TK, Worley 1025 KC, Wu D, Wu W, Wu YQ, Zhang X, Zou Z, Zucker H, Briscoe AD, Burmester T, Clem RJ, 1026 Feyereisen R, Grimmelikhuijzen CJP, Hamodrakas SJ, Hansson BS, Huguet E, Jermiin LS, Lan 1027 Q, Lehman HK, Lorenzen M, Merzendorfer H, Michalopoulos I, Morton DB, Muthukrishnan S, 1028 Oakeshott JG, Palmer W, Park Y, Passarelli AL, Rozas J, Schwartz LM, Smith W, Southgate A, 1029 Vilcinskas A, Vogt R, Wang P, Werren J, Yu XQ, Zhou JJ, Brown SJ, Scherer SE, Richards S, 1030 Blissard GW. 2016. Multifaceted biological insights from a draft genome sequence of the 1031 tobacco hornworm moth, Manduca sexta. Insect Biochemistry and Molecular Biolology 76:1181032 147. doi: 10.1016/j.ibmb.2016.07.005.

1033

1034

Keeling CI, Yuen MM, Liao NY, Docking TR, Chan SK, Taylor GA, Palmquist DL, Jackman SD, Nguyen A, Li M, Henderson H, Janes JK, Zhao Y, Pandoh P, Moore R, Sperling FA, Huber DP, Birol I, Jones SJ, Bohlmann J. 2013. Draft genome of the mountain pine beetle, Dendroctonus ponderosae Hopkins, a major forest pest. Genome Biology 14:R27. doi: 10.1186/gb-2013-14-3-r27.

Kraaijeveld K, Peter Neleman P, Mariën J, de Meijer E, Ellers J. 2018. Genomic resources for Goniozus legneri, Aleochara bilineata and Paykullia maculata, representing three independent origins of the parasitoid lifestyle in insects. BioRxiv doi: 10.1101/300418.

Li B, Predel R, Neupert S, Hauser F, Tanaka Y, Cazzamali G, Williamson M, Arakane Y, Verleyen P, Schoofs L, Schachtner J, Grimmelikhuijzen CJ, Park Y. 2008. Genomics, transcriptomics, and peptidomics of neuropeptides and protein hormones in the red flour beetle Tribolium castaneum. Genome Research 18:113-122. doi:10.1101/gr.6714008. Neuropeptidomic Analysis of the Stick Insect, Carausius morosus. Journal of Proteome Research 17:2192-2204. doi: 10.1021/acs.jproteome.8b00155. transiently expressed during non-feeding stages and reproductive dormancy. Scientific Reports 6:26620. doi: 10.1038/srep26620.

Lynch M, 2007. The origins of gene architecture. Sunderland (MA): Sinauer Associates, Inc. Publishers.

Marciniak P, Szymczak M, Pacholska-Bogalska J, Audsley N, Rosiński G. 2013. Identification and localisation of selected myotropic neuropeptides in the ventral nerve cord of tenebrionid 
1062 beetles. Comparative Biochemistry and Physiology. Part A, Molecular \& Integrative Physiology

1063 166:44-51. doi: 10.1016/j.cbpa.2013.05.008.

1064

1065

1066

1067

Mathelin J, Quennedey B, Bouhin H, Delachambre J. 1998. Characterization of two new cuticular genes specifically expressed during the post-ecdysial molting period in Tenebrio molitor. Gene 211:351-359. doi: org/10.1016/S0378-1119(98)00125-5.

1068

1069

McKenna DD, Scully ED, Pauchet Y, Hoover K, Kirsch R, Geib SM, Mitchell RF, Waterhouse

1070 RM, Ahn SJ, Arsala D, Benoit JB, Blackmon H, Bledsoe T, Bowsher JH, Busch A, Calla B,

1071 Chao H, Childers AK, Childers C, Clarke DJ, Cohen L, Demuth JP, Dinh H, Doddapaneni H, Dolan A, Duan JJ, Dugan S, Friedrich M, Glastad KM, Goodisman MA, Haddad S, Han Y, Hughes DS, Ioannidis P, Johnston JS, Jones JW, Kuhn LA, Lance DR, Lee CY, Lee SL, Lin H,

1074

1075 Lynch JA, Moczek AP, Murali SC, Muzny DM, Nelson DR, Palli SR, Panfilio KA, Pers D, Poelchau MF, Quan H, Qu J, Ray AM, Rinehart JP, Robertson HM, Roehrdanz R, Rosendale AJ, Shin S, Silva C, Torson AS, Jentzsch IM, Werren JH, Worley KC, Yocum G, Zdobnov EM, Gibbs RA, Richards S. 2016. Genome of the Asian longhorned beetle (Anoplophora glabripennis), a globally significant invasive species, reveals key functional and evolutionary innovations at the beetle-plant interface. Genome Biology 17:227. doi: 10.1186/s13059-0161088-8.

Meyer JM, Markov GV, Baskaran P, Herrmann M, Sommer RJ, Rödelsperger C. 2016. Draft Genome of the Scarab Beetle Oryctes borbonicus on La Réunion Island. Genome Biology and Evolution 8:2093-2105. doi: 10.1093/gbe/evw133.

Misof B, Liu S, Meusemann K, Peters RS, Donath A, Mayer C, Frandsen PB, Ware J, Flouri T, Beutel RG, Niehuis O, Petersen M, Izquierdo-Carrasco F, Wappler T, Rust J, Aberer AJ, Aspöck U, Aspöck H, Bartel D, Blanke A, Berger S, Böhm A, Buckley TR, Calcott B, Chen J, Friedrich F, Fukui M, Fujita M, Greve C, Grobe P, Gu S, Huang Y, Jermiin LS, Kawahara AY, Krogmann L, Kubiak M, Lanfear R, Letsch H, Li Y, Li Z, Li J, Lu H, Machida R, Mashimo Y, Kapli P, McKenna DD, Meng G, Nakagaki Y, Navarrete-Heredia JL, Ott M, Ou Y, Pass G, Podsiadlowski L, Pohl H, von Reumont BM, Schütte K, Sekiya K, Shimizu S, Slipinski A, Stamatakis A, Song W, Su X, Szucsich NU, Tan M, Tan X, Tang M, Tang J, Timelthaler G, Tomizuka S, Trautwein M, Tong X, Uchifune T, Walzl MG, Wiegmann BM, Wilbrandt J, Wipfler B, Wong TK, Wu Q, Wu G, Xie Y, Yang S, Yang Q, Yeates DK, Yoshizawa K, Zhang Q, Zhang R, Zhang W, Zhang Y, Zhao J, Zhou C, Zhou L, Ziesmann T, Zou S, Li Y, Xu X, Zhang Y, Yang H, Wang J, Wang J, Kjer KM, Zhou X. 2014. Phylogenomics resolves the timing and pattern of insect evolution. Science 346(6210):763-7. doi: 10.1126/science.1257570. allatotropin and allatotropin-like peptides from the silkworm, Bombyx mori. Peptides 34:98-105.

Nässel DR, Persson MG, Muren JE. 2000. Baratin, a nonamidated neurostimulating neuropeptide, isolated from cockroach brain: distribution and actions in the cockroach and locust nervous systems. Journal of Comparative Neurology 2000 Jun 26;422(2):267-86. doi: 
1108

1109

1110

1111

1112

1113

1114

1115

1116

1117

1118

1119

1120

1121

1122

1123

1124

1125

1126

1127

1128

1129

1130

1131

1132

1133

1134

1135

1136

1137

1138

1139

1140

1141

1142

1143

1144

1145

1146

1147

1148

1149

1150

1151

1152

1153

Neupert S. 2007. Novel members of the AKH/RPCH peptide family: isolation of AKH from the corpora cardiaca of the two beetle species, Cheilomenes lunata and Coccinella septempunctata. Pestycydy 2007:39-43.

Neupert S, Marciniak P, Köhler R, Nachman RJ, Suh CP, Predel R. 2018. Different processing of CAPA and pyrokinin precursors in the giant mealworm beetle Zophobas atratus

(Tenebrionidae) and the boll weevil Anthonomus grandis grandis (Curculionidae). General and Comparative Endocrinology 258:53-59. doi: 10.1016/j.ygcen.2017.08.026.

Olsen SS, Cazzamali G, Williamson M, Grimmelikhuijzen CJ, Hauser F. 2007. Identification of one capa and two pyrokinin receptors from the malaria mosquito Anopheles gambiae.

Biochemical and Biophysical Research Communications 362:245-251. doi: 10.1016/j.bbrc.2007.06.190.

Paluzzi JP, O'Donnell MJ. 2012. Identification, spatial expression analysis and functional characterization of a pyrokinin-1 receptor in the Chagas' disease vector, Rhodnius prolixus. Molecular and Cellular Endocrinology 363:36-45. doi: 10.1016/j.mce.2012.07.007.

Paluzzi JP, Park Y, Nachman RJ, Orchard I. 2010. Isolation, expression analysis, and functional characterization of the first antidiuretic hormone receptor in insects. Proceedings of the National Academy of Sciences of the United States of America 107:10290-10295. doi: 10.1073/pnas.1003666107.

Patel H, Orchard I, Veenstra JA, Lange AB. 2013. The distribution and physiological effects of three evolutionarily and sequence-related neuropeptides in Rhodnius prolixus: Adipokinetic hormone, corazonin and adipokinetic hormone/corazonin-related peptide. General and Comparative Endocrinology 195:1-8. doi: 10.1016/j.ygcen.2013.10.012.

Petersen TN, Brunak S, von Heijne G, Nielsen H. 2011. SignalP 4.0: discriminating signal peptides from transmembrane regions. Nature Methods 8:785-786. doi: 10.1038/nmeth.1701.

Proux JP, Miller CA, Li JP, Carney RL, Girardie A, Delaage M, Schooley DA. 1987. Identification of an arginine vasopressin-like diuretic hormone from Locusta migratoria. Biochemical and Biophysical Research Communications 149:180-186. doi: 10.1016/0006291X(87)91621-4

Reale V, Chatwin HM, Evans PD. 2004. The activation of G-protein gated inwardly rectifying $\mathrm{K}+$ channels by a cloned Drosophila melanogaster neuropeptide F-like receptor. European Journal of Neuroscience 19:570-576. doi: 10.1111/j.0953-816X.2003.03141.x.

Richards S, Gibbs RA, Weinstock GM, Brown SJ, Denell R, Beeman RW, Gibbs R, Beeman RW, Brown SJ, Bucher G, Friedrich M, Grimmelikhuijzen CJ, Klingler M, Lorenzen M, Richards S, Roth S, Schröder R, Tautz D, Zdobnov EM, Muzny D, Gibbs RA, Weinstock GM, Attaway T, Bell S, Buhay CJ, Chandrabose MN, Chavez D, Clerk-Blankenburg KP, Cree A, Dao M, Davis C, Chacko J, Dinh H, Dugan-Rocha S, Fowler G, Garner TT, Garnes J, Gnirke A,

PeerJ reviewing PDF | (2019:02:35410:1:1:NEW 24 Apr 2019) 
1154 Hawes A, Hernandez J, Hines S, Holder M, Hume J, Jhangiani SN, Joshi V, Khan ZM, Jackson

1155 L, Kovar C, Kowis A, Lee S, Lewis LR, Margolis J, Morgan M, Nazareth LV, Nguyen N,

1156 Okwuonu G, Parker D, Richards S, Ruiz SJ, Santibanez J, Savard J, Scherer SE, Schneider B,

1157 Sodergren E, Tautz D, Vattahil S, Villasana D, White CS, Wright R, Park Y, Beeman RW, Lord

1158 J, Oppert B, Lorenzen M, Brown S, Wang L, Savard J, Tautz D, Richards S, Weinstock G, Gibbs

1159 RA, Liu Y, Worley K, Weinstock G, Elsik CG, Reese JT, Elhaik E, Landan G, Graur D,

1160 Arensburger P, Atkinson P, Beeman RW, Beidler J, Brown SJ, Demuth JP, Drury DW, Du YZ,

1161 Fujiwara H, Lorenzen M, Maselli V, Osanai M, Park Y, Robertson HM, Tu Z, Wang JJ, Wang S,

1162 Richards S, Song H, Zhang L, Sodergren E, Werner D, Stanke M, Morgenstern B, Solovyev V,

1163 Kosarev P, Brown G, Chen HC, Ermolaeva O, Hlavina W, Kapustin Y, Kiryutin B, Kitts P,

1164 Maglott D, Pruitt K, Sapojnikov V, Souvorov A, Mackey AJ, Waterhouse RM, Wyder S,

1165 Zdobnov EM, Zdobnov EM, Wyder S, Kriventseva EV, Kadowaki T, Bork P, Aranda M, Bao R,

1166 Beermann A, Berns N, Bolognesi R, Bonneton F, Bopp D, Brown SJ, Bucher G, Butts T,

1167 Chaumot A, Denell RE, Ferrier DE, Friedrich M, Gordon CM, Jindra M, Klingler M, Lan Q,

1168 Lattorff HM, Laudet V, von Levetsow C, Liu Z, Lutz R, Lynch JA, da Fonseca RN, Posnien N,

1169 Reuter R, Roth S, Savard J, Schinko JB, Schmitt C, Schoppmeier M, Schröder R, Shippy TD,

1170 Simonnet F, Marques-Souza H, Tautz D, Tomoyasu Y, Trauner J, Van der Zee M, Vervoort M,

1171 Wittkopp N, Wimmer EA, Yang X, Jones AK, Sattelle DB, Ebert PR, Nelson D, Scott JG,

1172 Beeman RW, Muthukrishnan S, Kramer KJ, Arakane Y, Beeman RW, Zhu Q, Hogenkamp D,

1173 Dixit R, Oppert B, Jiang H, Zou Z, Marshall J, Elpidina E, Vinokurov K, Oppert C, Zou Z,

1174 Evans J, Lu Z, Zhao P, Sumathipala N, Altincicek B, Vilcinskas A, Williams M, Hultmark D,

1175 Hetru C, Jiang H, Grimmelikhuijzen CJ, Hauser F, Cazzamali G, Williamson M, Park Y, Li B,

1176 Tanaka Y, Predel R, Neupert S, Schachtner J, Verleyen P, Raible F, Bork P, Friedrich M,

1177 Walden KK, Robertson HM, Angeli S, Forêt S, Bucher G, Schuetz S, Maleszka R, Wimmer EA,

1178 Beeman RW, Lorenzen M, Tomoyasu Y, Miller SC, Grossmann D, Bucher G. 2008. The

1179 genome of the model beetle and pest Tribolium castaneum. Nature 452:949-955. doi:

$118010.1038 /$ nature06784.

1181

1182

1183

Roller L, Yamanaka N, Watanabe K, Daubnerová I, Zitnan D, Kataoka H, Tanaka Y. 2008. The unique evolution of neuropeptide genes in the silkworm Bombyx mori. Insect Biochemistry and

1184

1185

1186

1187

1188

1189

1190

1191

1192

1193 Molecular Biology 38:1147-1157. doi: 10.1016/j.ibmb.2008.04.009.

Rosenkilde C, Cazzamali G, Williamson M, Hauser F, Søndergaard L, DeLotto R, Grimmelikhuijzen CJP. 2003. Molecular cloning, functional expression, and gene silencing of two Drosophila receptors for the Drosophila neuropeptide pyrokinin-2. Biochemical and Biophysical Research Communications 309:485-494. doi: org/10.1016/j.bbrc.2003.08.022.

Schmitt F, Vanselow JT, Schlosser A, Kahnt J, Rössler W, Wegener C. 2015. Neuropeptidomics of the carpenter ant Camponotus floridanus. Journal of Proteome Research 14:1504-1514. doi: $10.1021 / \mathrm{pr} 5011636$.

1194

Schoville SD, Chen YH, Andersson MN, Benoit JB, Bhandari A, Bowsher JH, Brevik K, 
1200 Oppert B, Palli SR, Panfilio KA, Pauchet Y, Perkin LC, Petek M, Poelchau MF, Record É, 1201 Rinehart JP, Robertson HM, Rosendale AJ, Ruiz-Arroyo VM, Smagghe G, Szendrei Z, Thomas 1202 GWC, Torson AS, Vargas Jentzsch IM, Weirauch MT, Yates AD, Yocum GD, Yoon JS, 1203 Richards S. 2018. A model species for agricultural pest genomics: the genome of the Colorado 1204 potato beetle, Leptinotarsa decemlineata (Coleoptera: Chrysomelidae). Scientific Reports 1205 8:1931. doi: 10.1038/s41598-018-20154-1.

1206

1207

1208

1209

1210

1211

1212

1213

1214

1215

1216

1217

1218

1219

1220

1221

1222

1223

1224

1225

1226

1227

1228

1229

1230

1231

1232

1233

1234

1235

1236

1237

1238

1239

1240

1241

1242

1243
Spittaels K, Schoofs L, Grauwels L, Smet H, Van Damme J, Proost P, De Loof A. 1991. Isolation, identification and synthesis of novel oviductal motility stimulating head peptide in the Colorado potato beetle, Leptinotarsa decemlineata. Peptides 12:31-36. doi: 10.1016/01969781(91)90162-I.

Spittaels K, Vankeerberghen A, Torrekens S, Devreese B, Grauwels L, Van Leuven F, Hunt D, Shabanowitz J, Schoofs L, Van Beeumen J, De Loof A. 1995a. Isolation of Ala1-proctolin, the first natural analogue of proctolin, from the brain of the Colorado potato beetle. Molecular and Cellular Endocrinology 110:119-124. doi: 10.1016/0303-7207(95)03527-E.

Spittaels K, Vankeerberghen A, Schoofs L, Torrekens S, Grauwels L, Van Leuven F, De Loof A. 1995b. Identification, characterization, and immunological localization of a novel myotropic neuropeptide in the Colorado potato beetle, Leptinotarsa decemlineata. Peptides 16:365-374. doi: 10.1016/0196-9781(94)00205-K.

Spittaels K, Verhaert P, Shaw C, Johnston RN, Devreese B, Van Beeumen J, De Loof A. 1996a. Insect neuropeptide $\mathrm{F}(\mathrm{NPF})$-related peptides: isolation from Colorado potato beetle (Leptinotarsa decemlineata) brain. Insect Biochemistry and Molecular Biolology 26:375-382. doi: 10.1016/0965-1748(95)00104-2.

Spittaels K, Vankeerberghen A, Schoofs L, Proost P, Van Damme J, De Loof A. 1996b. Isolation and characterization of Locusta migratoria accessory gland myotropin I (Lom-Ag-MT-I) from the brain of the Colorado potato beetle, Leptinotarsa decemlineata. Archives of Insect Biochemistry and Physiology 31:149-155. doi: 10.1002/(SICI)1520-6327(1996)31:2<149::AID$\mathrm{ARCH} 3>3.0 . \mathrm{CO} ; 2-\mathrm{V}$.

Starratt AN, Brown BE. 1975. Structure of the pentapeptide proctolin, a proposed neurotransmitter in insects. Life Sciences 17:1253-1256.

Tarver MR, Huang Q, de Guzman L, Rinderer T, Holloway B, Reese J, Weaver D, Evans JD. 2016. Transcriptomic and functional resources for the small hive beetle Aethina tumida, a worldwide parasite of honey bees. Genomics Data 9:97-99. doi: 10.1016/j.gdata.2016.06.003.

Taylor PA 3rd, Bhatt TR, Horodyski FM. 1996. Molecular characterization and expression analysis of Manduca sexta allatotropin. European Journal of Biochemistry 239:588-596. doi: 10.1111/j.1432-1033.1996.0588u.x. 
1244 van Belleghem SM, Roelofs D, Van Houdt J, Hendrickx F. 2012. De novo transcriptome 1245 assembly and SNP discovery in the wing polymorphic salt marsh beetle Pogonus chalceus 1246 (Coleoptera, Carabidae). PLoS One 7:e42605. doi: 10.1371/journal.pone.0042605.

1247

1248

van Belleghem SM, Vangestel C, De Wolf K, De Corte Z, Möst M, Rastas P, De Meester L, Hendrickx F. 2018. Evolution at two time frames: Polymorphisms from an ancient singular divergence event fuel contemporary parallel evolution. PLoS Genetics 14:e1007796. doi:

1251 10.1371/journal.pgen.1007796.

1252

1253

1254

1255

1256

1257

1258

1259

1260

1261

1262

van Belleghem SM, Vangestel C, Wolf KD, Corte ZD, Möst M, Rastas P, Meester LD, Hendrickx F. 2018. Data from: Evolution at two time frames: polymorphisms from an ancient singular divergence event fuel contemporary parallel evolution. Dryad Digital Repository. doi: 10.5061/dryad.77r93d5

Vallejo DM, Juarez-Carreño S, Bolivar J, Morante J, Dominguez M. 2015. A brain circuit that synchronizes growth and maturation revealed through Dilp8 binding to Lgr3. Science 350:aac6767. doi: 10.1126/science.aac6767.

Veenstra JA. 1984. Immunocytochemical demonstration of a homology in peptidergic neurosecretory cells in the suboesophageal ganglion of a beetle and a locust with antisera to bovine pancreatic polypeptide, FMRFamide, vasopressin and alpha-MSH. Neuroscience Letters 48:185-90. doi: org/10.1016/0304-3940(84)90017-X.

Veenstra JA. 2000. Mono- and dibasic proteolytic cleavage sites in insect neuroendocrine peptide precursors. Archives of Insect Biochemistry and Physiology 43:49-63. doi: 10.1002/(SICI)1520-6327(200002)43:2<49::AID-ARCH1>3.0.CO;2-M.

1270

Veenstra JA. 2010. Neurohormones and neuropeptides encoded by the genome of Lottia gigantea, with reference to other mollusks and insects. General and Comparative Endocrinology 167:86-103. doi: 10.1016/j.ygcen.2010.02.010.

Veenstra JA. 2014. The contribution of the genomes of a termite and a locust to our understanding of insect neuropeptides and neurohormones. Frontiers in Physiology 5:454. doi: 10.3389/fphys.2014.00454.

Veenstra JA. 2016a. Similarities between decapod and insect neuropeptidomes. PeerJ 4:e2043. doi: 10.7717 peerj.2043.

Veenstra JA. 2016b. Allatostatins C, double C and triple C, the result of a local gene triplication in an ancestral arthropod. General and Comparative Endocrinology 230-231:153-157. doi: 10.1016/j.ygcen.2016.04.013.

Veenstra JA. 2016c. Neuropeptide evolution: Chelicerate neurohormone and neuropeptide genes may reflect one or more whole genome duplications. General and Comparative Endocrinology 229:41-55. doi: 10.1016/j.ygcen.2015.11.019. 
1290 Veenstra JA. 2017. The salivary gland salivation stimulating peptide from Locusta migratoria 1291 (Lom-SG-SASP) is not a typical neuropeptide. PeerJ 5:e3619. doi: 10.7717/peerj.3619.

1292

1293

1294

1295

1296

1297

1298

1299

1300

1301

Veenstra JA. 2019. Two Lys-vasopressin-like peptides, EFLamide, and other phasmid neuropeptides. General and Comparative Endocrinology pii: S0016-6480(18)30086-8. doi: 10.1016/j.ygcen.2018.04.027.

Veenstra JA, Ida T. 2014. More Drosophila enteroendocrine peptides: Orcokinin B and the CCHamides 1 and 2. Cell and Tissue Research 357:607-21. doi: 10.1007/s00441-014-1880-2.

Veenstra JA, Khammassi H. 2017. Rudimentary expression of RYamide in Drosophila melanogaster relative to other Drosophila species points to a functional decline of this

1302

1303

1304

1305 neuropeptide gene. Insect Biochemistry and Molecular Biolology 83:68-79. doi: 10.1016/j.ibmb.

Veenstra JA, Rodriguez L, Weaver RJ. 2012. Allatotropin, leucokinin and AKH in honey bees and other Hymenoptera. Peptides 35:122-130. doi: 10.1016/j.peptides.2012.02.019.

1306

1307

Veenstra JA, Romberg-Privee HM, Schooneveld H. 1984. Immunocytochemical localization of

1308

1309 peptidergic cells in the neuro-endocrine system of the Colorado potato beetle, Leptinotarsa

1310 decemlineata, with antisera against vasopressin, vasotocin and oxytocin. Histochemistry 81:2934. doi: 10.1007/BF00495397.

1311

1312

Vega FE, Brown SM, Chen H, Shen E, Nair MB, Ceja-Navarro JA, Brodie EL, Infante F, Dowd PF, Pain A. 2015. Draft genome of the most devastating insect pest of coffee worldwide: the

Verleyen P, Huybrechts J, Schoofs L. 2009. SIFamide illustrates the rapid evolution in Arthropod neuropeptide research. General and Comparative Endocrinology 162:27-35. doi: 10.1016/j.ygcen.2008.10.020.

Weaver RJ, Audsley N. 2008. Neuropeptides of the beetle, Tenebrio molitor identified using MALDI-TOF mass spectrometry and deduced sequences from the Tribolium castaneum genome. Peptides 29:168-178. doi: 10.1016/j.peptides.2007.09.020.

Wegener C, Gorbashov A. 2008. Molecular evolution of neuropeptides in the genus Drosophila. Genome Biololgy 9:R131. doi: 10.1186/gb-2008-9-8-r131.

Wu YM, Li J, Chen XS. 2018. Draft genomes of two blister beetles Hycleus cichorii and Hycleus phaleratus. Gigascience 7:1-7. doi: 10.1093/gigascience/giy006.

Yamanaka N, Hua YJ, Mizoguchi A, Watanabe K, Niwa R, Tanaka Y, Kataoka H. 2005. Identification of a novel prothoracicostatic hormone and its receptor in the silkworm Bombyx mori. Journal of Biological Chemistry 280:14684-14690. doi: 10.1074/jbc.M500308200. 
1336 biosynthesis by innervating peptidergic neurons. Proceedings of the National Academy of 1337 Sciences of the United States of America 103:8622-8627. doi: 10.1073/pnas.0511196103.

1338

1339 Zhang SQ, Che LH, Li Y, Dan Liang, Pang H, Ślipiński A, Zhang P. 2018. Evolutionary history 1340 of Coleoptera revealed by extensive sampling of genes and species. Nature Commununications 1341 9:205. doi: 10.1038/s41467-017-02644-4. 


\section{Figure 1}

\section{Coleoptera Pigment Dispersing Factors}

Alignment of the predicted PDFs from the seventeen Coleoptera species as obtained by conceptual translation of their putative transcripts. Drosophila PDF has been added for comparison. The sequences include the processing sites on both side of the mature peptide. The species are arranged according to their position on the phylogenetic tree as established by Zhang and colleagues (2018). Note the differences between the predicted PDF from the single Adephaga species, green on the tree, the Cucujiformia, purple part of the tree, and the remaining Polyphaga species.



\section{Figure 2}

\section{Coleoptera Neuropeptide F}

Alignment of the predicted NPFs from sixteen species as obtained by conceptual translation of their putative transcripts. The sequences include the processing sites on C-terminal site of the mature peptide. The species are arranged according to their position on the phylogenetic tree as established by Zhang and colleagues (2018). Note the differences between the predicted NPF from Cucujiformia where the peptide has acquired a cysteine bridge with those from the other species. An NPF gene was not found in the Oryctes genome, even though this species does have an NPF receptor gene.



\section{Figure 3}

Coleoptera ACPs

Alignment of the predicted Coleoptera ACPs as obtained by conceptual translation of their putative transcripts. The sequences include the processing sites on C-terminal site of the mature peptide. Cleavage of the $\mathrm{N}$-terminal is performed by a signal peptidase. The species are arranged according to their position on the phylogenetic tree as established by Zhang and colleagues (2018). Tree branches have been made red where the peptide and its receptor were lost from the genome, which must have occurred on at least three occasions. Note that the peptide sequence is not very well conserved.

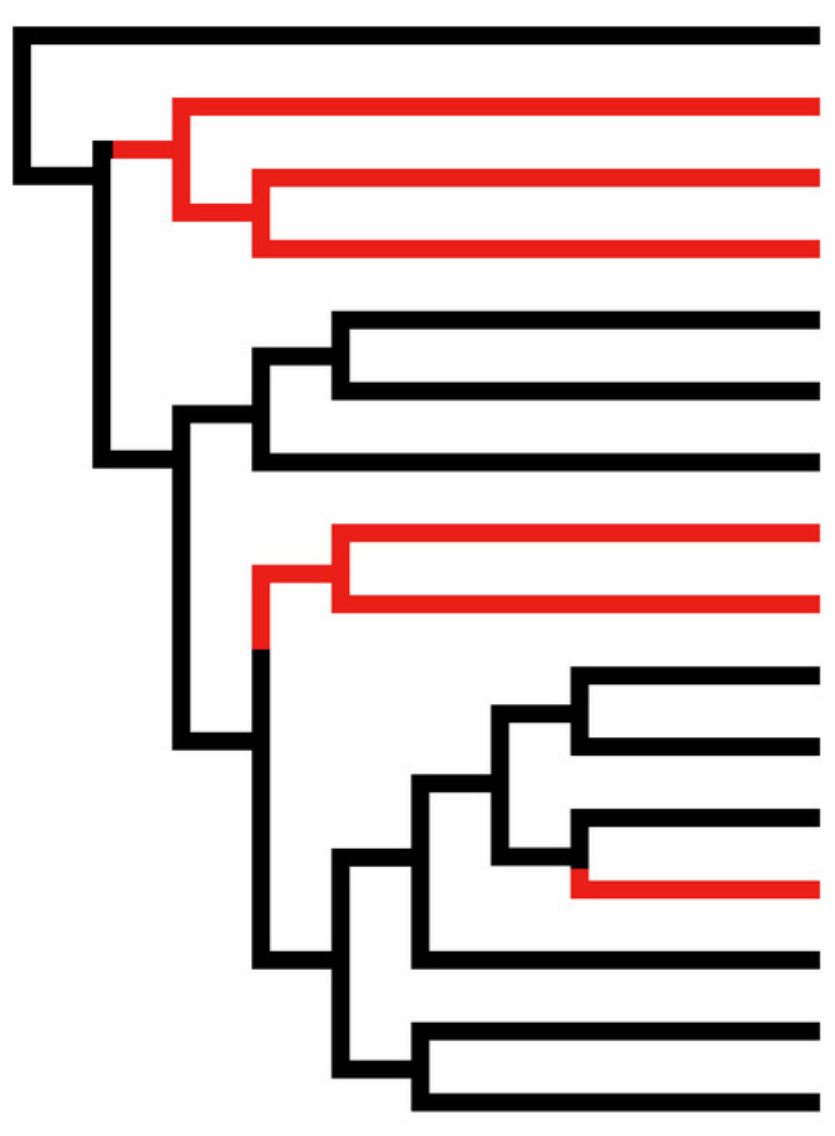

Pogonus Ignelater

Photinus

Aquatica

Nicrophorus

Aleochara

Oryctes

Coccinella

Harmonia

Dendroctonus

Hypothenemus

Anoplophora

Leptinotarsa

Aethina

Hycleus

Tribolium
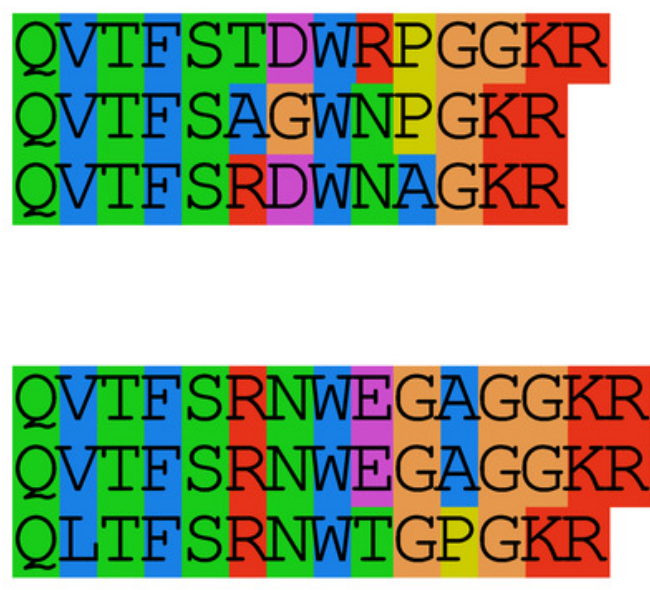

QVTFSRDWNPGKR QVTFSRDWNPGKR QVTESRDWNPGKR 


\section{Figure 4}

Unusual calcitonin sequences.

Alignment of calcitonin B sequences encoded by the Leptinotarsa calcitonin B gene and the first such gene from Anoplophora. Note that with the exception of the sixth peptide from Leptinotarsa, these peptides have well conserved amino acid sequences, but that some of them have a cysteine bridge in the N-terminal of the molecule, while others have not. All peptides are predicted to have a C-terminal amide.

Anoplophora-1 Anoplophora-2 Anoplophora-3 Anoplophora-4 Anoplophora-5 Leptinotarsa-1 Leptinotarsa-2 Leptinotarsa-3 Leptinotarsa-4 Leptinotarsa-5 Leptinotarsa-6

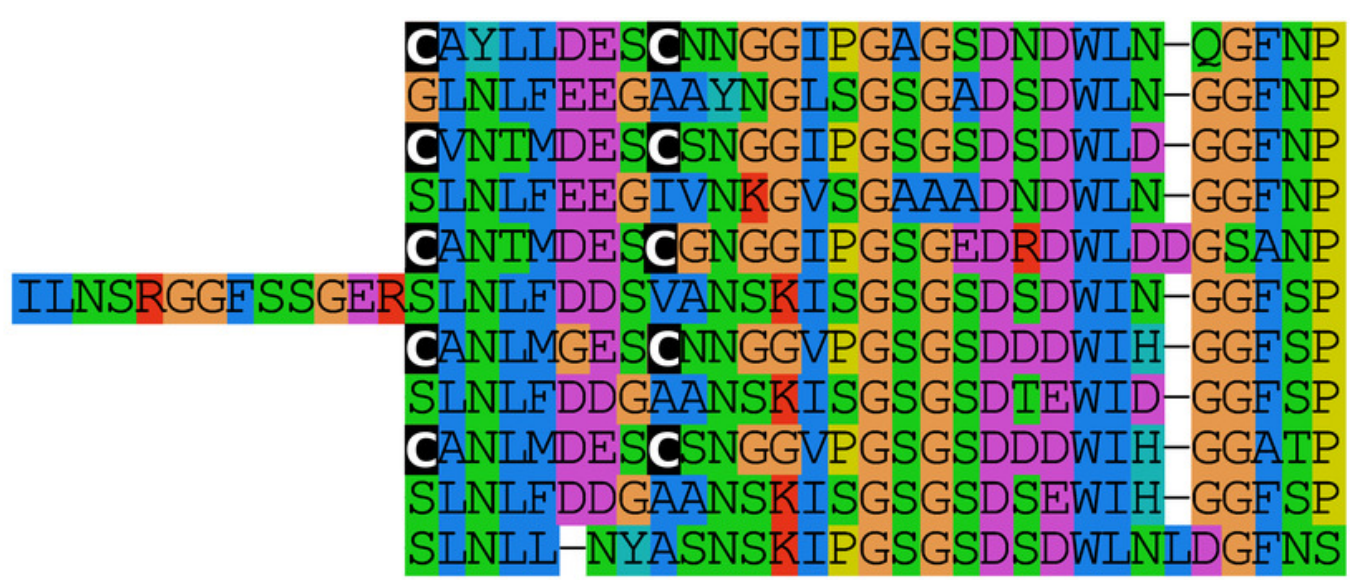




\section{Figure 5}

Coleoptera Elevenins.

Alignment of the predicted Coleoptera elevenins as obtained by conceptual translation of their putative transcripts. The sequences include the processing sites of peptides; where these are lacking on the $\mathrm{N}$-terminal, cleavage is obtained by a signal peptidase. The species are arranged according to their position on the phylogenetic tree as established by Zhang and colleagues (2018). Tree branches have been made red where the peptide and its receptor were lost from the genome, which must have occurred on at least three occasions. Note that the peptide sequence is not very well conserved and that in both Dendroctonus and Hypothenemus an additional cysteine bridge has been added to the peptide.


KVIDCSPLPECCRTFVFSPGCRGVAAKR RVANCRPLPQCCRKYVYSPACRGAAAKR QRKIDCRKFVFAPPCRGIAAKR

ASPRLYADREDKQDCEKIIDCRVYVHYPICRGIAAKR GTRRKINCRKYVHAPECRGIAAKR ALVKNPNLLKKNHCRTHIFSPVCRGQQKR SAIKGPDNEKKSQFSLTSYCRKHILSPPCRGHQKR 


\section{Figure 6}

Neuropeptide losses.

Loss of eight neuropeptide signaling systems in at least one of the sixteen Coleoptera species for which a genome is available. Black branches on the tree indicates the presence of the neuropeptide gene, while red branches indicate its absence. In the case of LGR3 only the receptor could be studied, but for ACP, elevenin, RYamide, natalisin, leucokinin and relaxin both ligand and receptor genes were absent from the indicated genomes. Relaxin and calcitonin are neuropeptides for which the receptor has not been formally deorphanized in insects. Their identities have been deduced from sequence similarity between the insect ligands with their well known vertebrate homologs, sequence similarity between their putative receptors and their vertebrate homologs and the systematic co-occurrence and coabsence in the same genomes of each ligand with its putative receptor (cf Veenstra, 2014). A, leucokinin; B, ACP; C, natalisin; D, calcitonin; E, elevenin; F, relaxin; G, RYamide; H, LGR3.
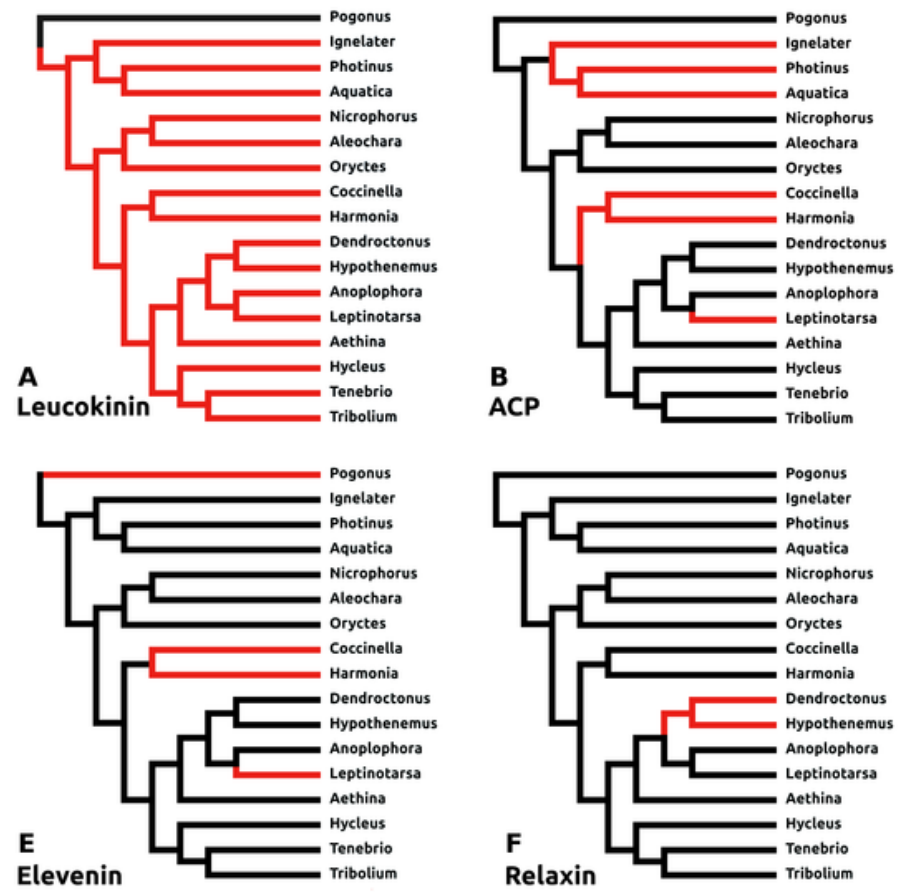



\section{Figure 7}

Adipokinetic hormones.

Putative AKH precursor sequences found in the sixteen genomes and the Tenebrio

transcriptome. Most of the sequences are relatively short and are aligned in the top part of the figure. Those sequences typically consists of four different parts: the signal peptide, followed immediately by the AKH sequence and a glycine residue that is transformed into the C-terminal amide and a convertase cleavage site, a variable region, and at the end the sequence of a well conserved peptide forming a disulfide bridge. These different regions are indicated below the alignment. Two sequences that show homology to AKH precursors deviate significantly from this pattern. The second Harmonia AKH-like precursor is predicted to produce a very long AKH-like peptide, while the second Aethina precursor lacks a signal peptide and hence can not produce AKH.

Pogonus
Ignelater
Photinus
Aquatica
Nicrophorus
Aleochara
Oryctes
Coccinella
Harmonia-1
Dendroctonus
Hypothenemus
Anoplophora-1
Anoplophora-2
Leptinotarsa-1
Leptinotarsa-2
Aethina-1
Hycleus-1
Hycleus-2
Tenebrio
Tribolium-1
Tribolium-2

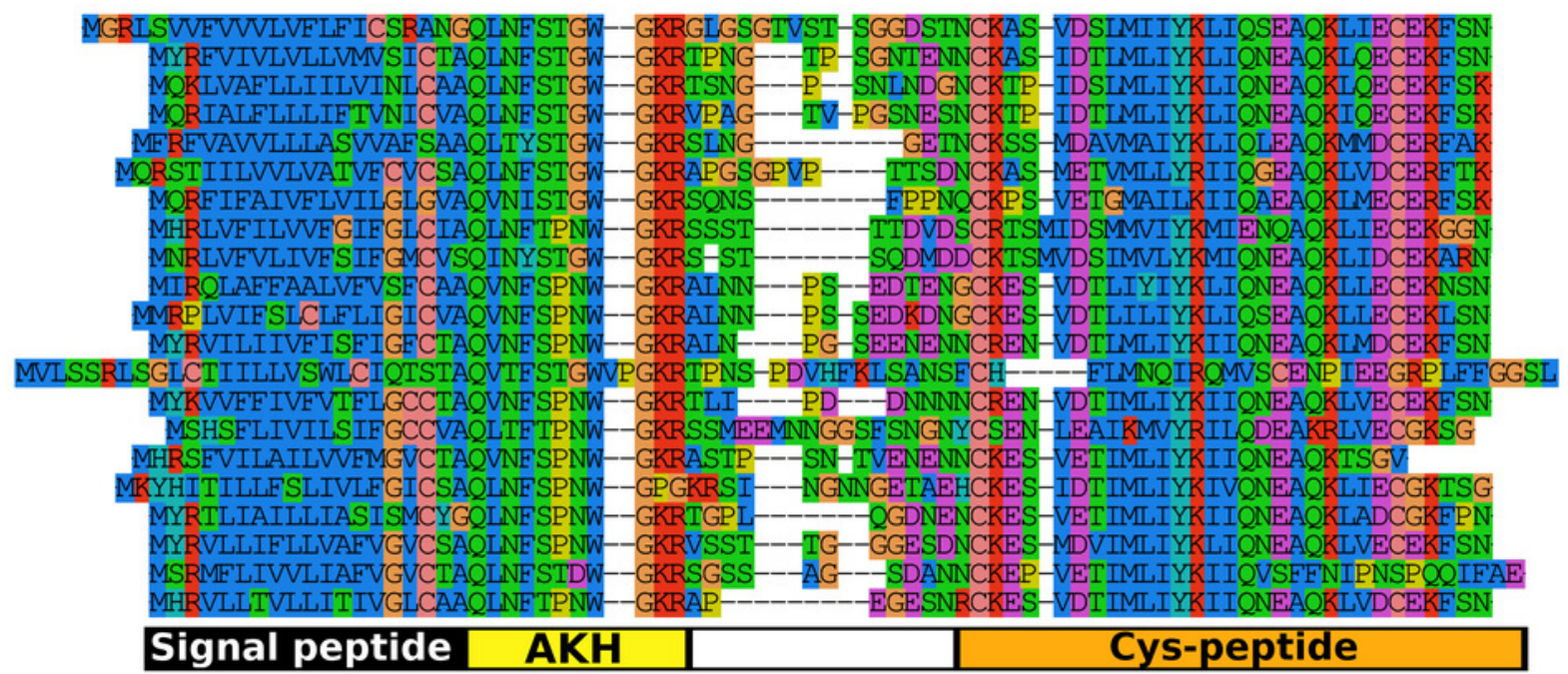

Harmonia-2

MNRFVEIVAFSIFGICVSQLNFTPYWLIPEEKLIPRQKPMPNSWIQPNAWTNQPWPKRYSNSQDMDHCKIPMIDSMMVVYEMIQKEAERLIDCEKAKN
\begin{tabular}{l|c|c|} 
Signal peptide & AKH & Cys-peptide \\
\hline
\end{tabular}




\section{Figure 8}

\section{Leptinotarsa CCHamides.}

Duplication of the CCHamide 2 neuropeptide and the CCHamide 1 receptor genes in Leptinotarsa. a. Schematic organization of the three CCHamide genes in Leptinotarsa. Horizontal lines indicate introns and other untranslated DNA sequences, the boxes correspond to translated exons. Yellow indicates sequences corresponding to the signal peptides, purple correspond to the mature peptide sequences and green the remainder of the precursors. Note that the gene organizations of CCHamides $2 a$ and $2 b$ are very similar. $b$. Direct comparison of the predicted mature peptides. Note that CCHamide $2 \mathrm{~b}$ lacks a Cterminal amide that is present in all other CCHamides. c. Direct comparison of the predicted precursors for $\mathrm{CCHamides} 2 \mathrm{a}$ and $2 \mathrm{~b}$. Note that, although similar, these sequences are significantly different. Asterisks (*) indicate identical amino acid residues, double dots (:) and single dots (.) indicated conserved and semi-conserved substitutions of amino acid residues respectively. $d$. Simple phylogenetic tree for $\mathrm{CCHamide}$ receptors from Leptinotarsa, other Coleoptera and $D$. melanogaster. Note that the two Leptinotarsa CCHamide 1 receptors are more similar to one another than to any of the other Coleoptera CCHamide 1 receptors, including the one from Anoplophora. Nucleotide sequences for these receptors are: ACZ94340.1, XP_023021283.1; XP_017768833.1, XP_019758999.1; XP_025836439.1, XP_008197479.1, XP_023310960.1, XP_019880954.1; XP_018332710.1, ERL86066.1, XP_019880542.1, XP_023313148.1, XP_015838444.1; XP_017779615.1, AAF57819.3, XP_023023025.1 and the Leptinotarsa CCHamide 2 receptor which is present in the supplementary excel file. 

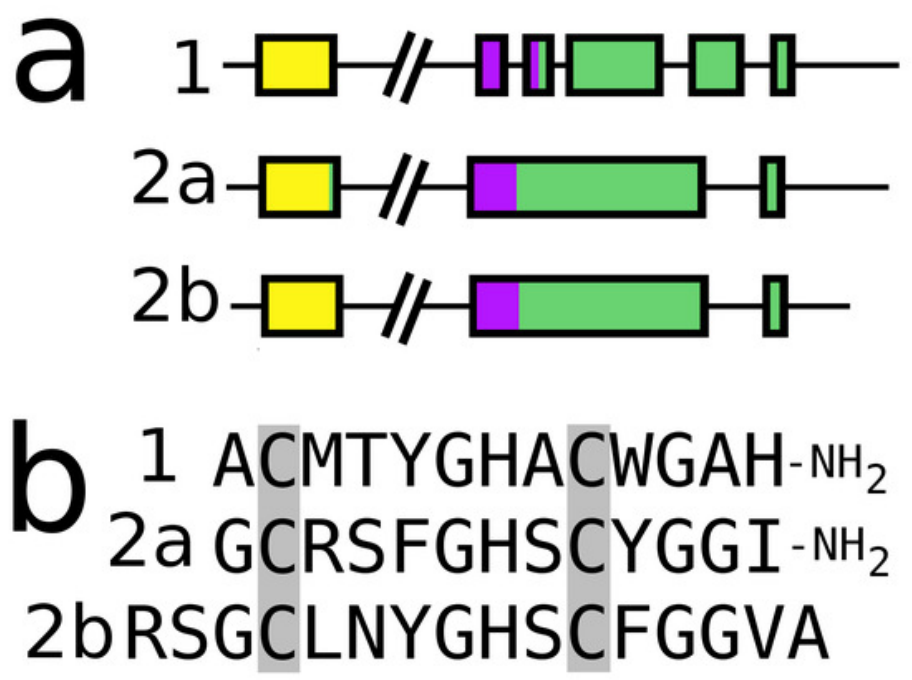

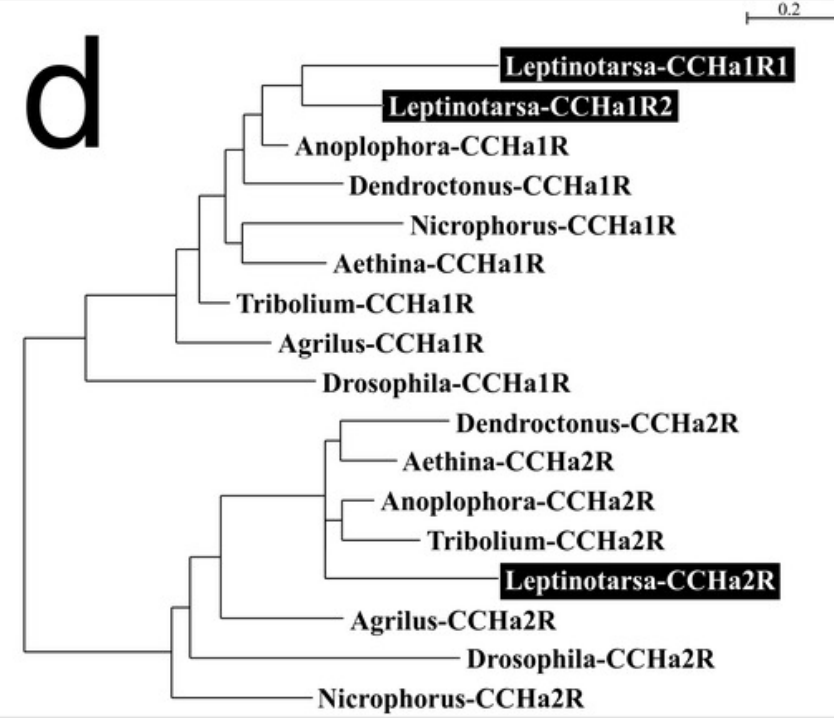

noplophora-CCHa1R Nicrophorus-CCHa1R thina-CCHa1R

um-CCHa1R -Dendroctonus-CCHa2R - Aethina-CCHa2R Leptinotarsa-CCHa2R Nicrophorus-CCHa2R
$\mathrm{CCHa} 2 \mathrm{a}$

$\mathrm{CCHa} 2 \mathrm{~b}$

$\mathrm{CCHa} 2 \mathrm{a}$

$\mathrm{CCHa} 2 \mathrm{~b}$
MSYYTVIQLFVITLMLVCSGAEVEGKRGCRSFGHSCYGGIGKRNPGLLNASN - - - N MFHFVATLAFILVLSTITEGRSGCLNYGHSCFGGVAKRHNDQNEYSEGEKY $::: . . \quad::: \quad .:{ }^{* *}:{ }^{* *} .:{ }^{* * *}:{ }^{* *}:{ }^{* *}: . \quad:{ }^{*}:$

FEKPEYILPS - -AWGPFRSNQLQIRNPPKMGQLSAIIAQWISNFKEAQNMPRTSTA FQNDENVESTDNQRFLYQSEQPQIFLEPRYAEQLRIFRQWLQHHRMAFPAN

$$
{ }^{*}::^{*}:::^{*}:{ }^{*}{ }^{*}: .:{ }^{*}:{ }^{*}: .:::^{*}
$$




\section{Figure 9}

Nicrophorus allatostatin CCC gene.

a. schematic representation of the allatostatin CCC gene in Nicrophorus. Boxes indicate exons and horizontal lines introns. The first exon (white) is untranslated, the second (yellow) codes for the signal peptide and few additional amino acid residues. The last coding exon has two acceptor splice sites. $b$. When the first acceptor splice site is used the mRNA is larger and leads to the production of an mRNA that contains coding sequences for two allatostatin CCC-like peptides, however an inframe stop codon prevents translation of the second one. When the second acceptor splice site is used, it is the second allatostatin CCC peptide that will be produced. $c$. The last amino acid residues coded by the two types of mRNA. Convertase cleavage sites and C-terminal dibasic amino acid residues that will be removed by carboxypeptidases are highlighted. The Aleochara gene has a very similar structure, although the untranslated first exon could not be identified. Note that the sequences of these peptides are fairly similar between the two species, and that in both cases the peptides produced from the first transcript lack the C-terminal dibasic amino acid residues that are typically present in allatostatin CCC peptides (Veenstra, 2016b). 

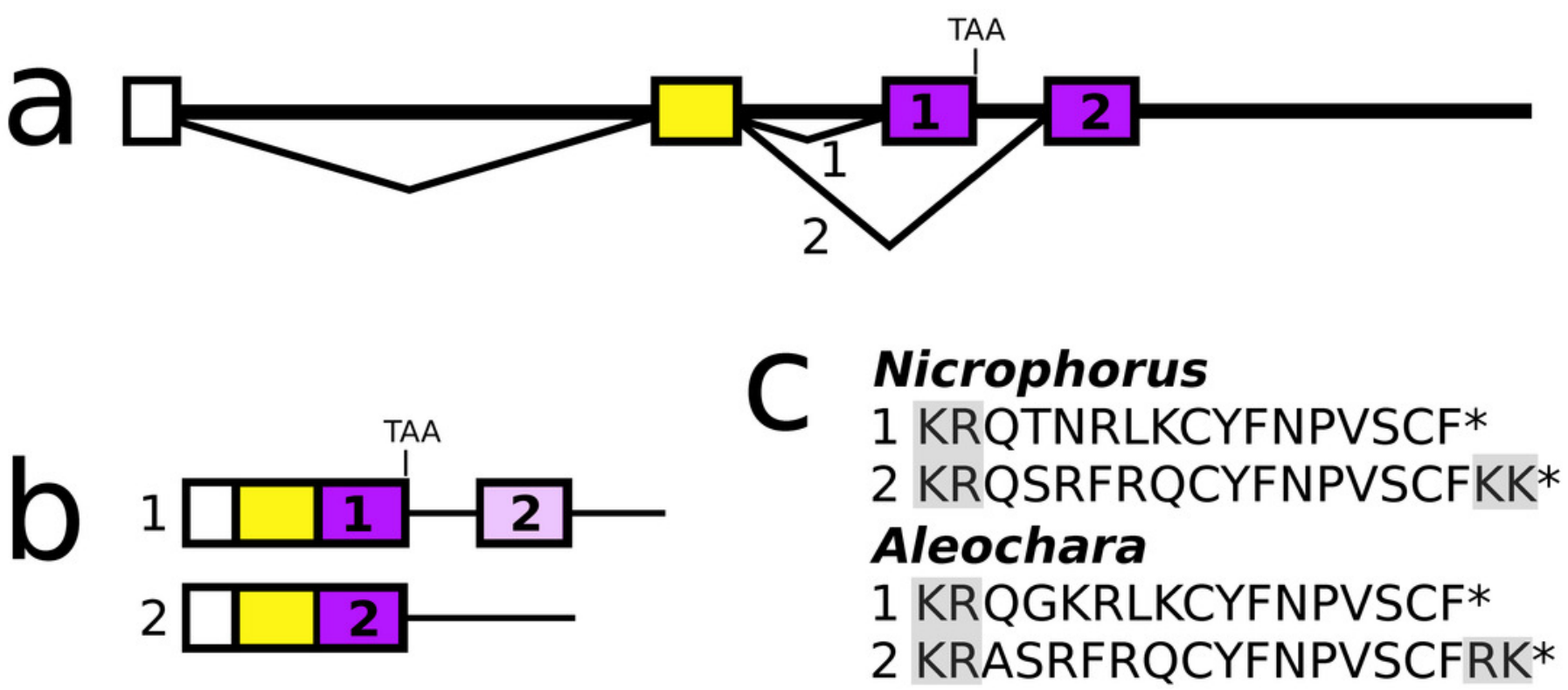


\section{Figure 10}

Structure of allatotropin genes.

Horizontal lines indicate non-translated DNA and the boxes coding exons. Yellow shows the location of the coding sequences for the signal peptide, purple those for allatotropins and green those for the remainder of the precursors. On two occasions the number of allatotropin paracopies was increased during evolution; red branches in the tree. Once by adding a coding exon, and once by adding a paracopy inside the original allatotropin coding exon. The last coding exons for the Aleochara and Oryctes allatotropins could not be established. The structure of the Tenebrio gene is translucent to indicate that it is only inferred from those of Hycleus and Tribolium based on the very similar sequences of their respective allatotropin transcripts.

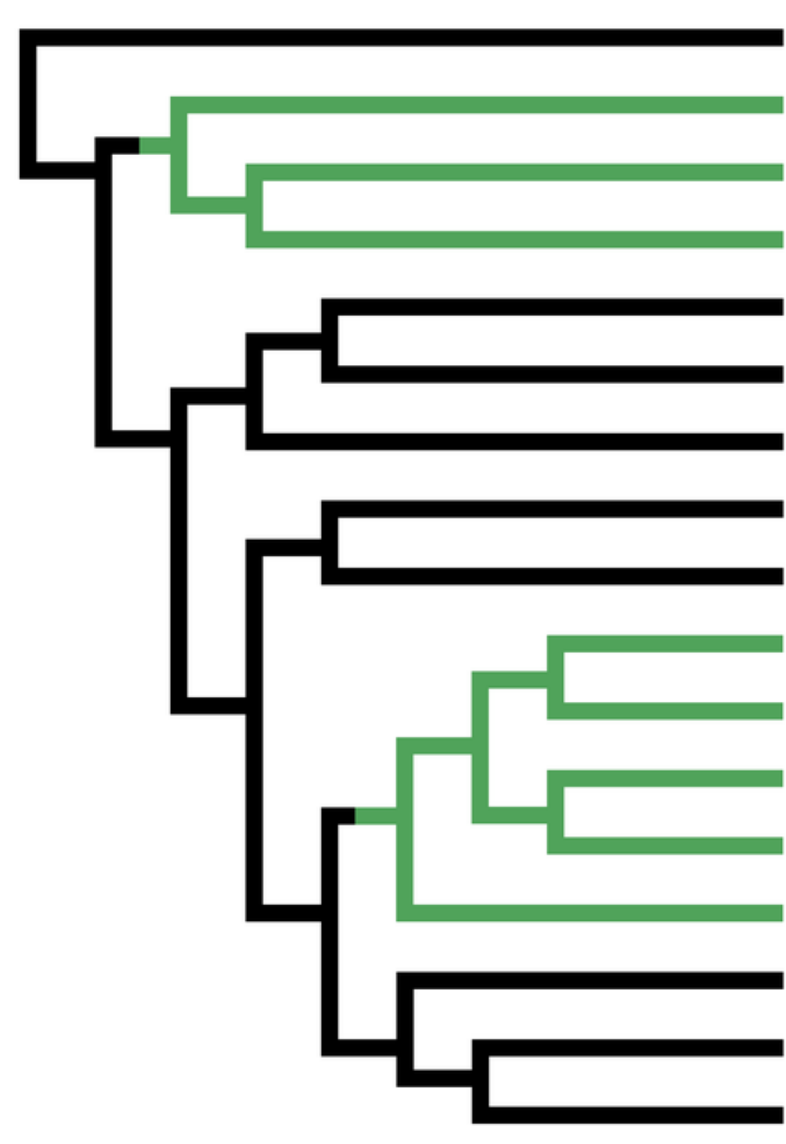

Pogonus
Ignelater
Photinus
Aquatica
Nicrophorus
Aleochara
Oryctes
Coccinella
Harmonia
Dendroctonus
Hypothenemus
Anoplophora
Leptinotarsa
Aethina
Hycleus
Tenebrio
Tribolium

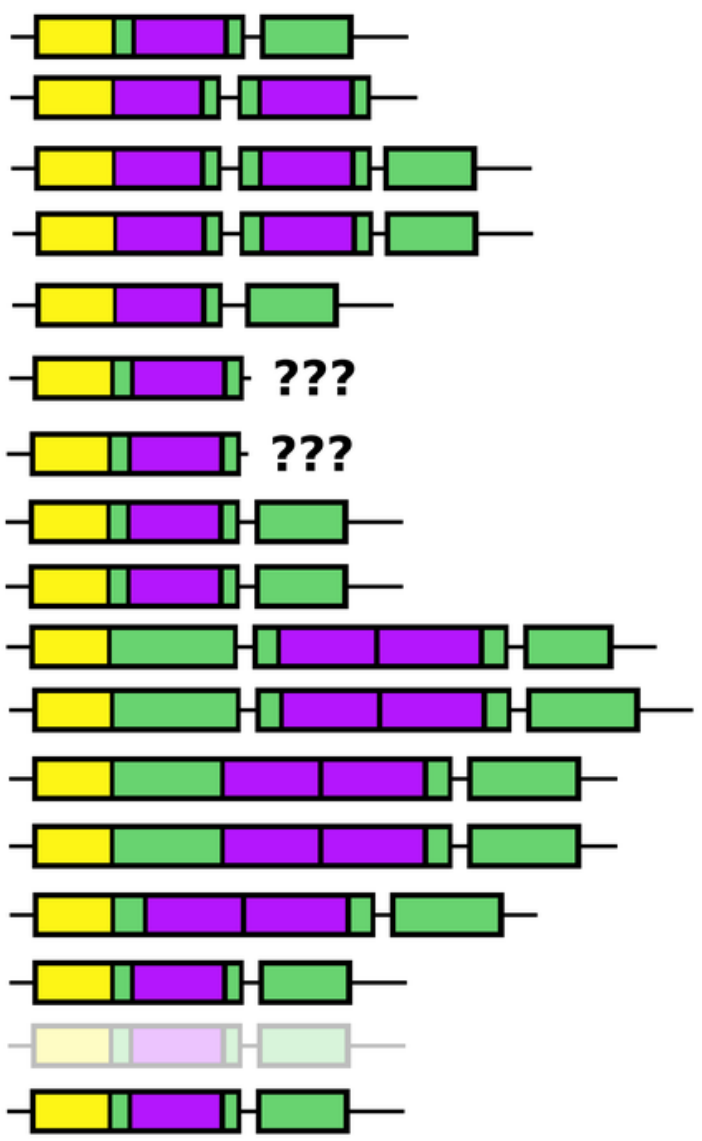




\section{Figure 11}

Structure of DH31 genes.

A. DH31 gene structures. B. D31 transcript structures. Horizontal lines indicate nontranslated DNA and the boxes coding exons. Yellow shows the location of the coding sequences for the signal peptide coding, orange those for a coding exon common to all transcripts, black coding exons for $\mathrm{DH} 31$ itself and green and purple those for other putative neuropeptides. The structure of the Tenebrio gene is translucent to indicate that it is only inferred from those of Hycleus and Tribolium based on the very similar sequences of their respective DH31 transcripts. To the left is a phylogenetic tree in order to facilitate comparing sequences with evolution, to the right are the various transcripts that are produced from these genes by alternative splicing.

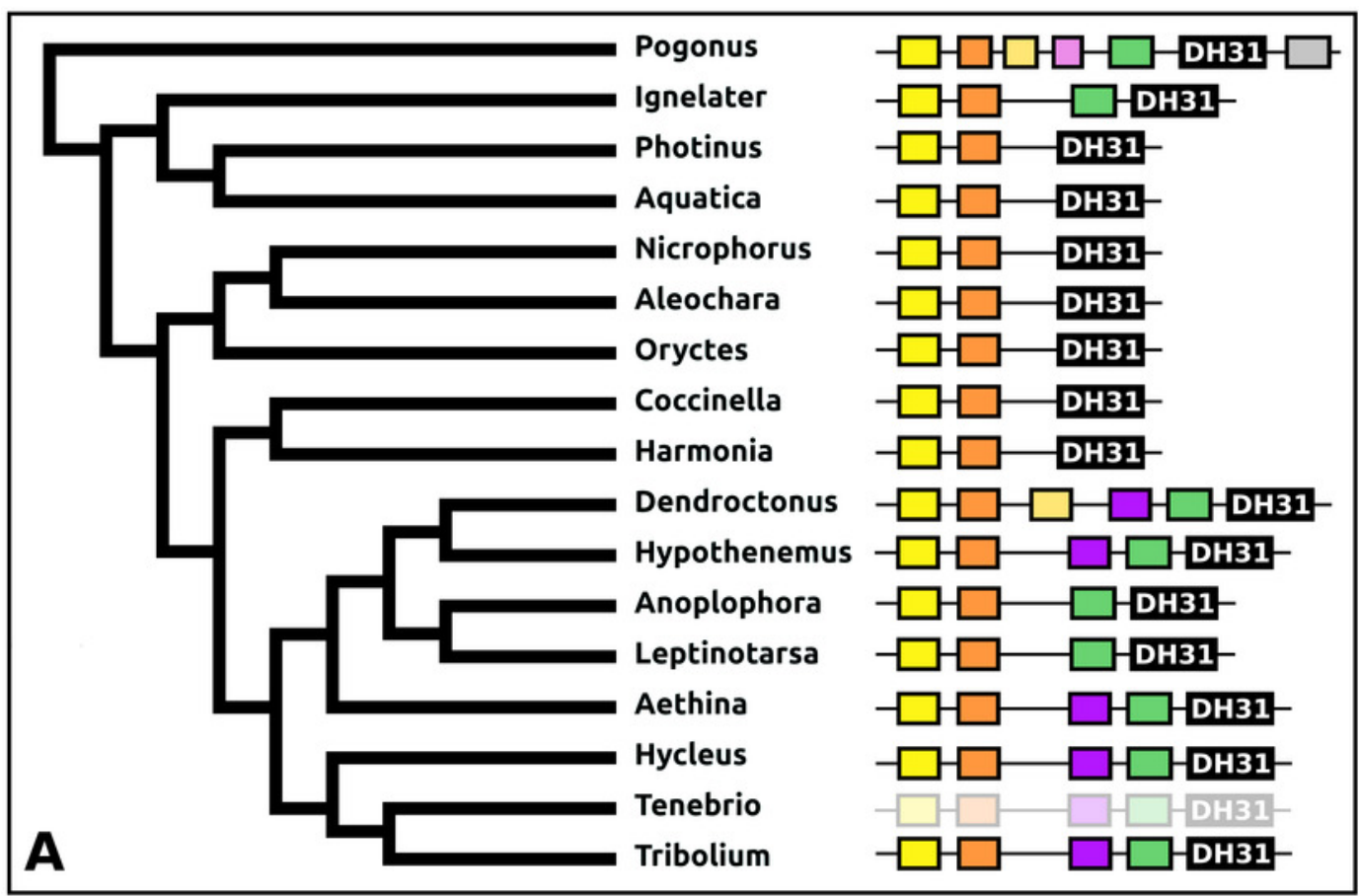

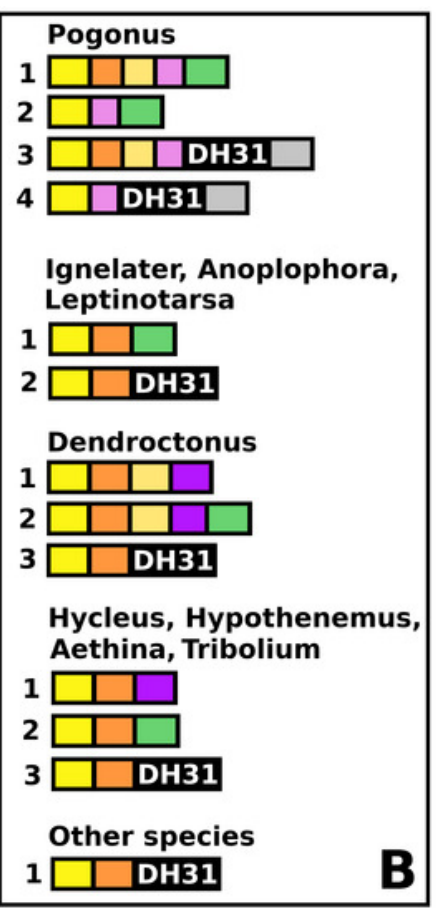




\section{Figure 12}

Structure of D37-D47 genes.

A. DH37-DH47 gene structures. B. DH37-DH4747 transcript structures. Horizontal lines indicate non-translated DNA and the boxes coding exons. Yellow shows the first coding exon containing sequences coding the signal peptide and parts of the precursor, the purple coding exon contains the complete sequence for $\mathrm{DH} 37$, its convertase cleavage sites and few additional amino acid residues on each site, and the green coding exon contains the same for DH47. Note that the DH37 exon is only present in the Cucujiformia, corresponding to the magenta part of the tree. The DH37 coding exon has been duplicated in Aethina and allows the DH37-DH47 gene to produce three different transcripts and three different putative diuretic hormones. The structure of the Tenebrio gene is translucent to indicate that it is only inferred from those of Hycleus and Tribolium based on the very similar sequences of their respective $\mathrm{DH} 37$ and $\mathrm{DH} 47$ transcripts. To the right are the various transcripts that are produced from these genes by alternative splicing. 


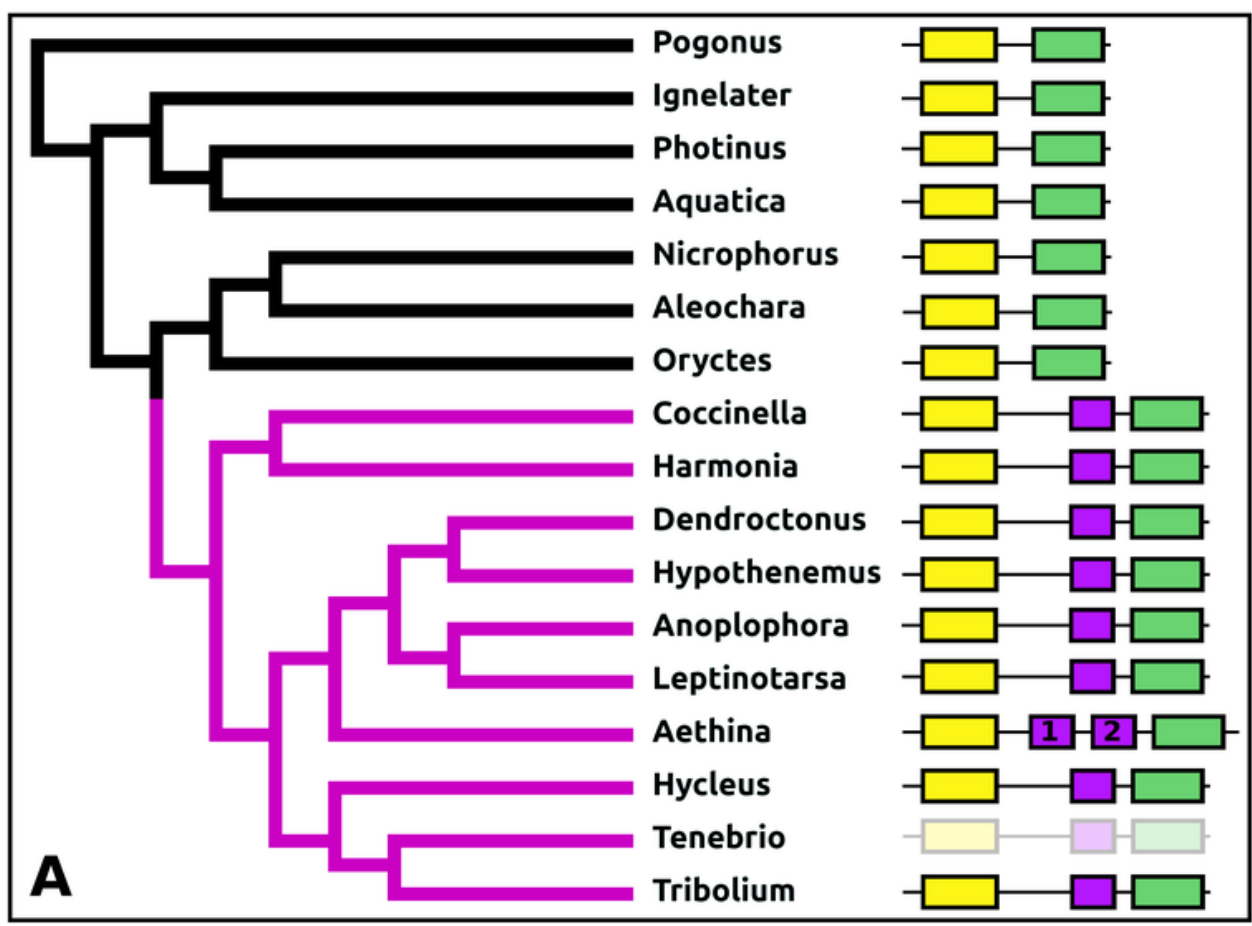

Pogonus, Ignelater,

Photinus, Aquatica

Nicrophorus, Aleochara, Oryctes

10

Coccinella, Harmonia,

Dendroctonus, Hypothenemus,

Anoplophora, Leptinotarsa,

Hycleus, Tenebrio, Tribolium

$1 \square$

$2 \square$

Aethina

1 \begin{tabular}{|l|l|}
\hline & 1 \\
\hline
\end{tabular}

2 \begin{tabular}{|l|l|}
\hline & 2 \\
\hline
\end{tabular}

$3 \square$ 


\section{Figure 13}

Structure of periviscerokinin genes.

A. Periviscerokinin gene structures. B. Periviscerokinin transcript structures. Horizontal lines indicate non-translated DNA and the boxes coding exons. Yellow shows the first coding exon containing the sequence coding the signal peptide and parts of the precursor, the purple coding exons contain sequences for a periviscerokinin, and the green coding exon sequences for a periviscerokinin, a tryptopyrokinin and another periviscerokinin. The final exon, black in the figure, characteristically codes for several acidic amino acid residues. In general there are relatively few RNAseq reads for this gene and when there are gaps in the genome assembly, as is the case in Leptinotarsa and Harmonia, it is not possible to reconstruct the complete gene. The structure of the Tenebrio gene is translucent to indicate that it is only inferred from those of Hycleus and Tribolium based on the very similar sequences of their periviscerokinin transcripts. To the right are the various transcripts that are produced from these genes by alternative splicing. Note that there may well be additional transcripts that could not be identified due to the scarcity of RNAseq reads for this gene. 


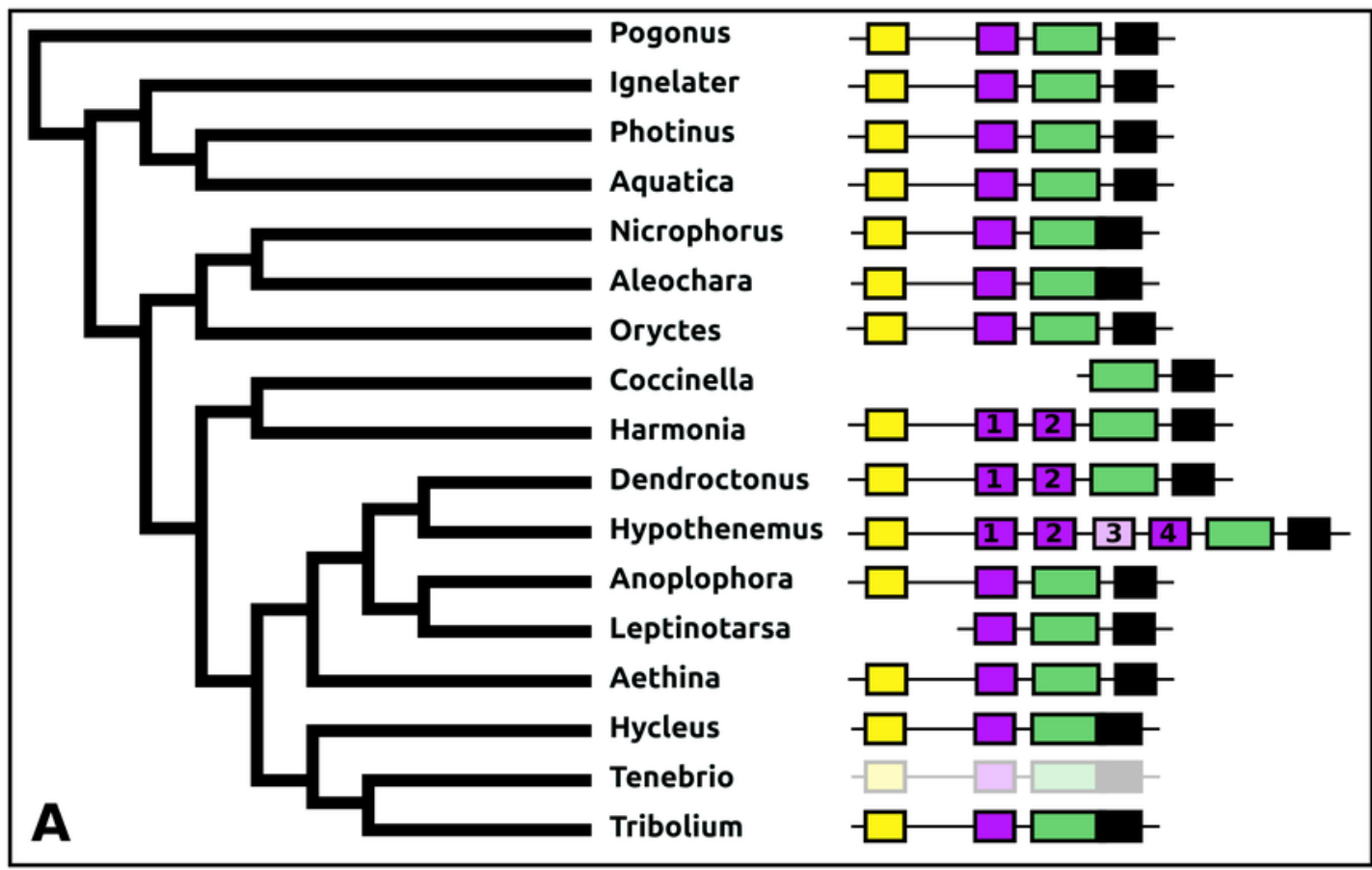

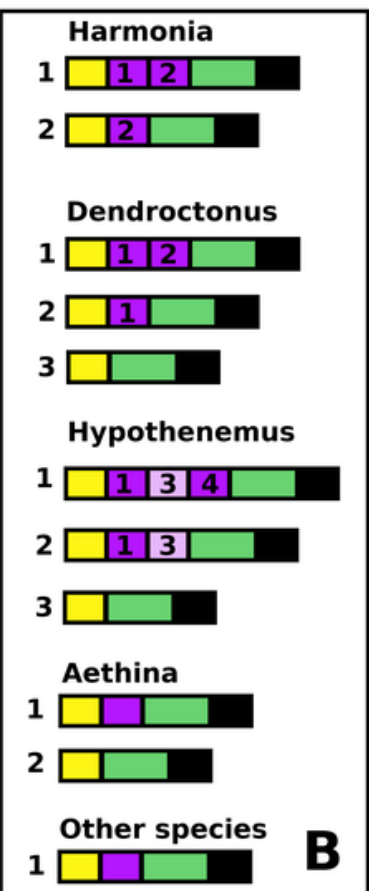




\section{Figure 14}

SNPF precursors.

Partial tree of four species with the structure of their SNPF genes. In all species except Anoplophora and Leptinotarsa the sNPF gene consists of three coding exons. The first one (yellow) codes coding for the signal peptide and a few additional amino acid residues, the second one (orange) codes for a well conserved sequence and near the end of the exon has the sequence for SNPF (indicated in green), while the last ones codes for a peptide that is not very well conserved. In both Anoplophora and Leptinotarsa there is an additional exon between the second and third that codes for an additional sNPF paracopy. In Leptinotarsa, RNAseq data suggests a single mRNA encompassing all four of these exons in Leptinotarsa, but alternative splicing allowing the production of SNPF precursors that have either one or two sNPF paracopies in Anoplophora.

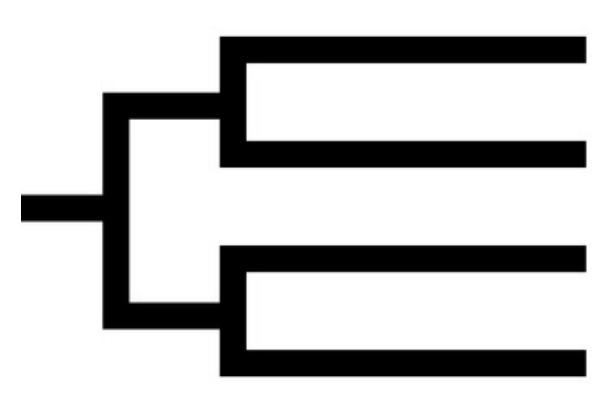

Dendroctonus Hypothenemus Anoplophora Leptinotarsa
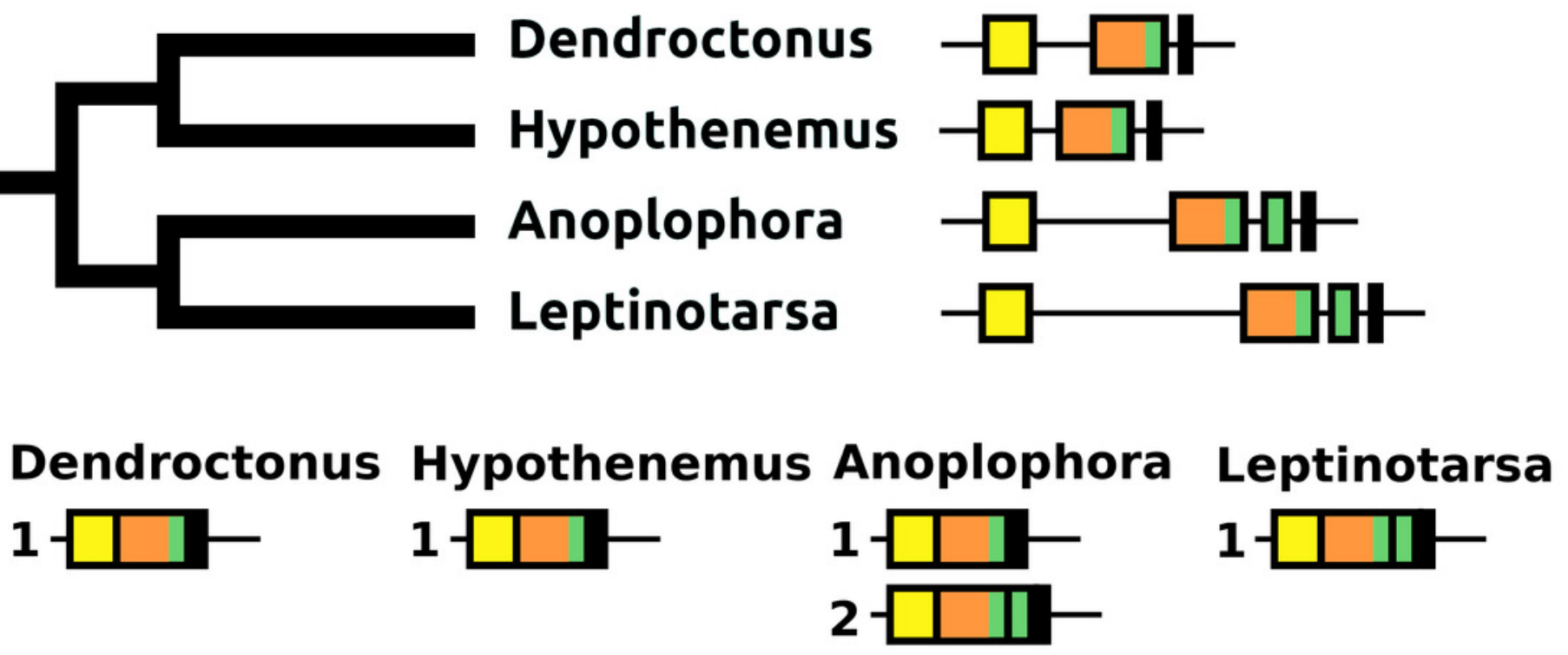